\title{
Catalytically Cleavable Detergent for Membrane Protein Studies
}

Lu Liu, $\$$ Zhihao Zhu, Fang Zhou, Dongxiang Xue, Tao Hu, Weiling Luo, Yanli Qiu, Dong Wu, Fei Zhao, ${ }^{*}$ Zhiping Le, ${ }^{*}$ and Houchao Tao*

Emails: zhaofei@shanghaitech.edu.cn; zple@ncu.edu.cn;

taohch@shanghaitech.edu.cn

\section{TABLE OF CONTENTS}

\begin{tabular}{|l|l|}
\hline Figure S1 & Positions of A30C mutation site of MsbA. \\
\hline Figure S2 & Thermal stability of membrane proteins in CatCDs, DDM and LMNG. \\
\hline Table S1 & Evaluation of CatCDs' cleavage in different metal catalysts. \\
\hline Figure S3 & $\begin{array}{l}\text { Evaluation of CatCD-1's cleavage in differed palladium catalysts detected } \\
\text { by ELSD-HPLC. }\end{array}$ \\
\hline Figure S4 & $\begin{array}{l}\text { Time course of CatCD-1's cleavage mediated by [Pd(allyl)Cl }]_{2} \text { in three } \\
\text { different buffer solutions. }\end{array}$ \\
\hline Figure S5 & $\begin{array}{l}\text { Evaluation of CatCD-1's cleavage in organic solvents detected by ELSD- } \\
\text { HPLC. }\end{array}$ \\
\hline Figure S6 & Cleavage of CatCD-1 in the presence of typical detergents. \\
\hline Figure S7 & SEC-profiling of MsbA in the treatment of [Pd(allyl)Cl $]_{2}$. \\
\hline Figure S8 & $\begin{array}{l}\text { SEC-profiling of MsbA before and after detergents exchanged in CCD-2 or } \\
\text { CatCD-1. }\end{array}$ \\
\hline Table S2 & Commercial detergents for reconstitution studies of MsbA. \\
\hline $\begin{array}{l}\text { Experimental } \\
\text { section }\end{array}$ & General methods for synthetic chemistry \\
\hline Scheme S1 & Synthesis of CatCDs \\
\hline NMR spectra \\
\hline Purity characterization \\
\hline References & \\
\hline
\end{tabular}




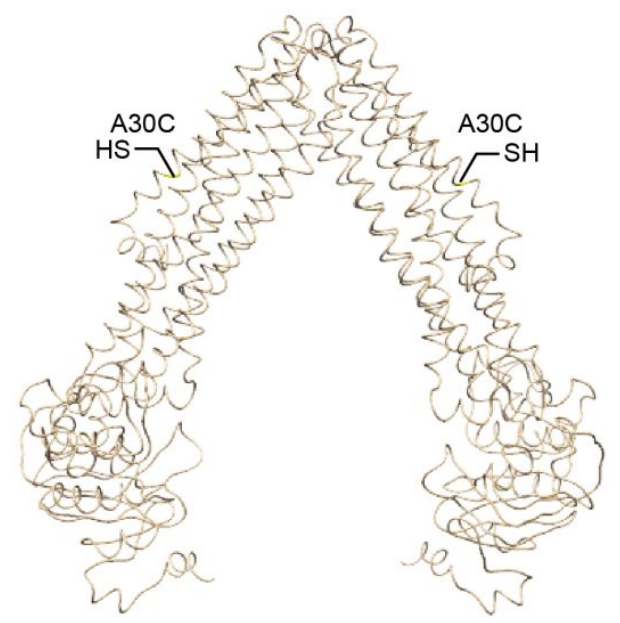

Figure S1. Positions of A30C mutation site of MsbA. 

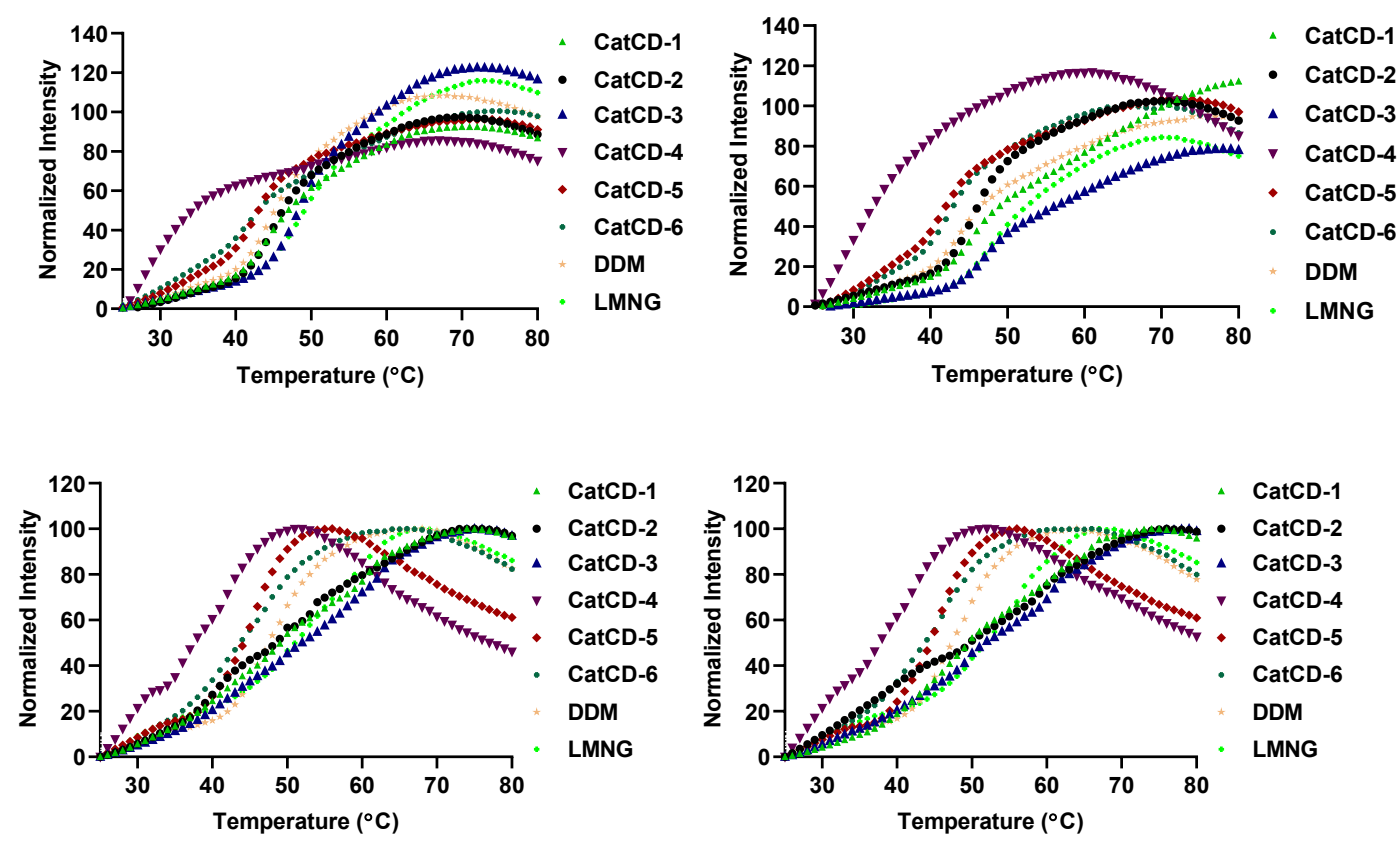

\begin{tabular}{|c|c|c|c|c|c|c|c|c|}
\hline Detergent & CatCD-1 & CatCD-2 & CatCD-3 & CatCD-4 & CatCD-5 & CatCD-6 & DDM & LMNG \\
\hline $\mathbf{T}_{\mathbf{m}} /{ }^{\circ} \mathbf{C}$ & 46.3 & 45.9 & 50.0 & 21.5 & 42.4 & 42.2 & 45.7 & 50.6 \\
\hline $\mathbf{T}_{\mathbf{m}} /{ }^{\circ} \mathbf{C}$ & 51.5 & 46.2 & 51.6 & 31.8 & 41.4 & 42.2 & 46.1 & 49.8 \\
\hline $\mathbf{T}_{\mathbf{m}} /{ }^{\circ} \mathbf{C}$ & 48.0 & 46.5 & 50.8 & 35.1 & 42.6 & 42.6 & 47.0 & 50.2 \\
\hline $\mathbf{T}_{\mathbf{m}} /{ }^{\circ} \mathbf{C}$ & 49.0 & 47.4 & 51.6 & 35.3 & 42.9 & 42.5 & 46.5 & 50.9 \\
\hline
\end{tabular}
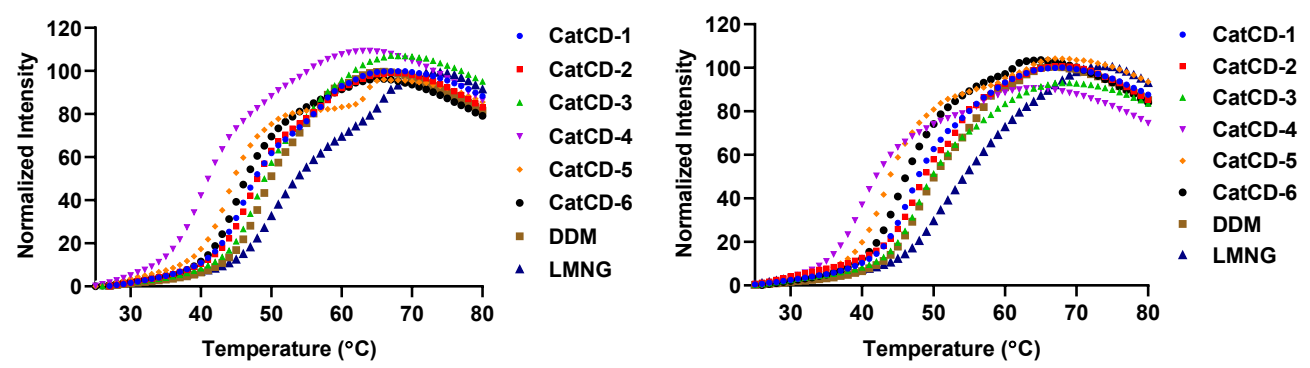

\begin{tabular}{|c|c|c|c|c|c|c|c|c|}
\hline Detergent & CatCD-1 & CatCD-2 & CatCD-3 & CatCD-4 & CatCD-5 & CatCD-6 & DDM & LMNG \\
\hline $\mathbf{T}_{\mathbf{m}} /{ }^{\circ} \mathbf{C}$ & 47.6 & 48.3 & 49.0 & 40.6 & 43.9 & 45.7 & 49.6 & 53.9 \\
\hline $\mathbf{T}_{\mathbf{m}} /{ }^{\circ} \mathbf{C}$ & 47.4 & 47.3 & 49.3 & 40.9 & 44.1 & 45.6 & 49.2 & 53.1 \\
\hline
\end{tabular}

Figure S2. Thermal stability of MsbA (up) and $\mathrm{A}_{2 \mathrm{~A}} \mathrm{AR}$ (down) in CatCDs, DDM and LMNG. Thermal shift assays were repeated twice. 
Table S1. Evaluation of CatCDs' cleavage in different metal catalysts.

\begin{tabular}{|c|c|c|c|c|c|c|}
\hline Catalyst & CatCD-1 & CatCD-2 & CatCD-3 & CatCD-4 & CatCD-5 & CatCD-6 \\
\hline$[\mathrm{Pd}(\text { allyl }) \mathrm{Cl}]_{2}$ & $>99.0 \%$ & $<1.0 \%$ & $23.8 \%$ & $<1.0 \%$ & $13.4 \%$ & $6.9 \%$ \\
\hline $\mathrm{Pd}(\mathrm{OAc})_{2}$ & $>99.0 \%$ & $<1.0 \%$ & $38.9 \%$ & $41.6 \%$ & $45.5 \%$ & $15.6 \%$ \\
\hline $\operatorname{Pd}(\mathrm{TFA})_{2}$ & $>99.0 \%$ & $29.4 \%$ & $29.1 \%$ & $53.7 \%$ & $30.6 \%$ & $26.0 \%$ \\
\hline $\mathrm{PdCl}_{2}$ & $>99.0 \%$ & $13.3 \%$ & $10.4 \%$ & $48.0 \%$ & $6.9 \%$ & $13.7 \%$ \\
\hline $\mathrm{Na}_{2} \mathrm{PdCl}_{4}$ & $>99.0 \%$ & $11.0 \%$ & $17.6 \%$ & $44.0 \%$ & $9.1 \%$ & $16.5 \%$ \\
\hline $\operatorname{Pd}(\mathrm{dba})_{2}$ & $61.5 \%$ & $<1 \%$ & $13.4 \%$ & $28.2 \%$ & $16.2 \%$ & $6.3 \%$ \\
\hline $\mathrm{RuCl}_{3}$ & $38.4 \%$ & $41.5 \%$ & $8.7 \%$ & $<1 \%$ & $11.9 \%$ & $10.1 \%$ \\
\hline $\mathrm{K}_{2} \mathrm{PtCl}_{4}$ & $26.1 \%$ & $20.1 \%$ & $<1.0 \%$ & $27.2 \%$ & $<1.0 \%$ & $<1.0 \%$ \\
\hline $\mathrm{K}_{2} \mathrm{PtCl}_{6}$ & $1.2 \%$ & $5.9 \%$ & $<1.0 \%$ & $<1 \%$ & $<1.0 \%$ & $<1.0 \%$ \\
\hline $\mathrm{CoCl}_{2}$ & $53.4 \%$ & $33.7 \%$ & $4.2 \%$ & $8.1 \%$ & $<1.0 \%$ & $4.0 \%$ \\
\hline $\mathrm{Co}_{2}(\mathrm{CO})_{8}$ & $41.4 \%$ & $46.1 \%$ & $13.4 \%$ & $7.4 \%$ & $2.6 \%$ & $16.9 \%$ \\
\hline $\mathrm{NiCl}_{2}$ & $18.6 \%$ & $<1 \%$ & $<1.0 \%$ & $<1 \%$ & $15.1 \%$ & $6.1 \%$ \\
\hline $\mathrm{Ni}(\mathrm{OAc})_{2}$ & $29.2 \%$ & $33.2 \%$ & $20.6 \%$ & $<1 \%$ & $11.6 \%$ & $2.1 \%$ \\
\hline $\mathrm{Cu}(\mathrm{OAc})_{2}$ & $49.7 \%$ & $39.3 \%$ & $<1.0 \%$ & $2.3 \%$ & $<1.0 \%$ & $1.6 \%$ \\
\hline
\end{tabular}

Reagents and conditions: $1 \mathrm{mM}$ CatCDs, $0.1 \mathrm{mM}$ catalyst, in $\mathrm{ddH}_{2} \mathrm{O}, 4{ }^{\circ} \mathrm{C}, 8 \mathrm{~h}$. The residue of CatCDs was measured under an isocratic elution with $40 \% \mathrm{MeCN}(1 \mathrm{~mL} / \mathrm{min})$ by ELSD-HPLC for three times. The residual percentage of CatCDs were calculated based on the inner standard octyl glucoside $(1 \mathrm{mM})$. 


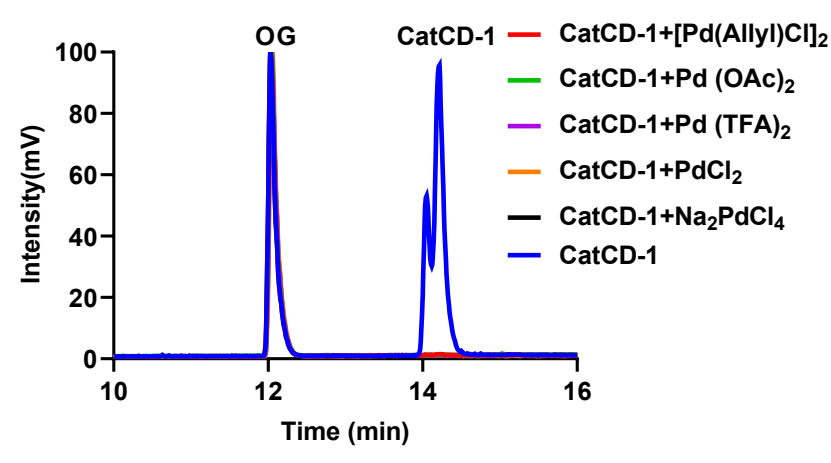

Figure S3. Evaluation of CatCD-1's cleavage in differed palladium catalysts detected by ELSD-HPLC. Reagents and conditions: $1 \mathrm{mM}$ CatCD-1, $0.1 \mathrm{mM}$ catalyst, $\mathrm{ddH}_{2} \mathrm{O}$, $4{ }^{\circ} \mathrm{C}, 8 \mathrm{~h} .1 \mathrm{mM}$ octyl glucoside was used as internal standard. 

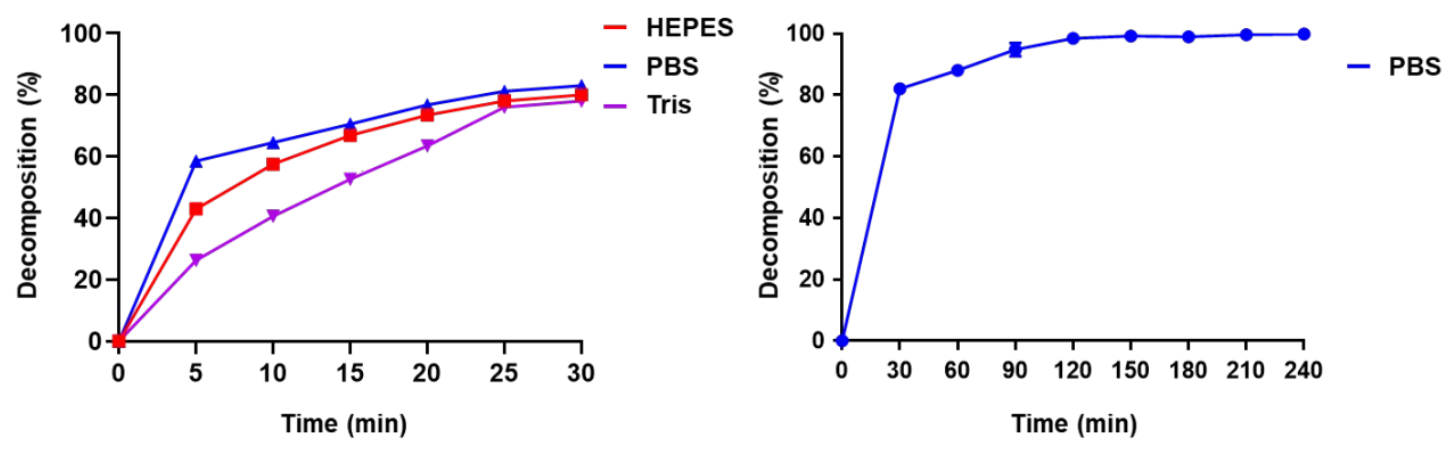

Figure S4. Time course of CatCD-1's cleavage mediated by $[\mathrm{Pd}(\text { allyl }) \mathrm{Cl}]_{2}$ in three different buffer solutions. Reagents and conditions: $1 \mathrm{mM}$ CatCD-1, $0.05 \mathrm{mM}$ $[\mathrm{Pd}(\text { allyl }) \mathrm{Cl}]_{2}, 20 \mathrm{mM}$ buffers, $\mathrm{pH} 7.5,4{ }^{\circ} \mathrm{C}$. 

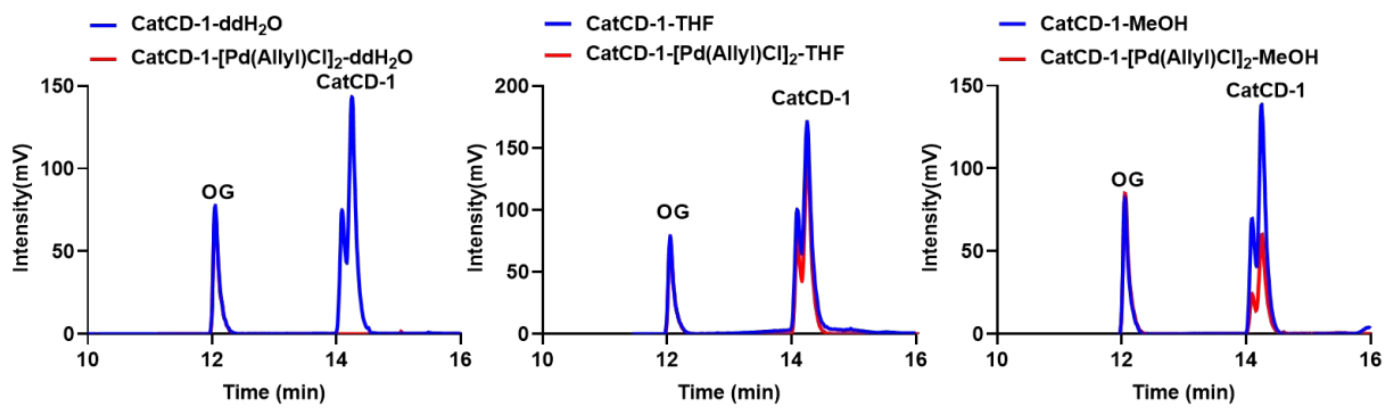

Figure S5. Evaluation of CatCD-1's cleavage in organic solvents detected by ELSDHPLC. Reagents and conditions: $1 \mathrm{mM}$ CatCD-1, $0.05 \mathrm{mM}[\mathrm{Pd}(\text { allyl }) \mathrm{Cl}]_{2}$, in $\mathrm{ddH}_{2} \mathrm{O}$, THF or $\mathrm{CH}_{3} \mathrm{OH}$ at $4{ }^{\circ} \mathrm{C}$ for $8 \mathrm{~h}$. $1 \mathrm{mM} \mathrm{OG}$ was used as internal standard. 

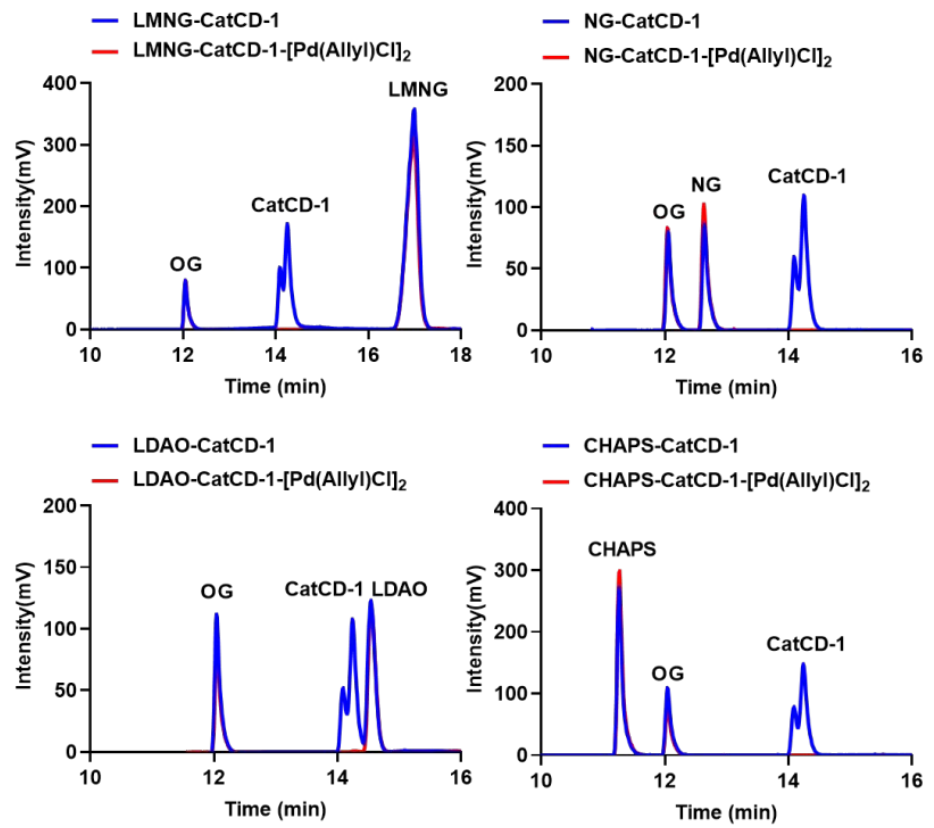

Figure S6. Cleavage of CatCD-1 in the presence of typical detergents. Reagents and conditions: $1 \mathrm{mM}$ CatCD-1, $1 \mathrm{mM}$ test detergents, $0.05 \mathrm{mM}[\mathrm{Pd}(\text { allyl }) \mathrm{Cl}]_{2}$, in $\mathrm{ddH}_{2} \mathrm{O}$, THF or $\mathrm{CH}_{3} \mathrm{OH}$ at $4{ }^{\circ} \mathrm{C}$ for $8 \mathrm{~h}$. $1 \mathrm{mM} \mathrm{OG}$ was used as internal standard. 

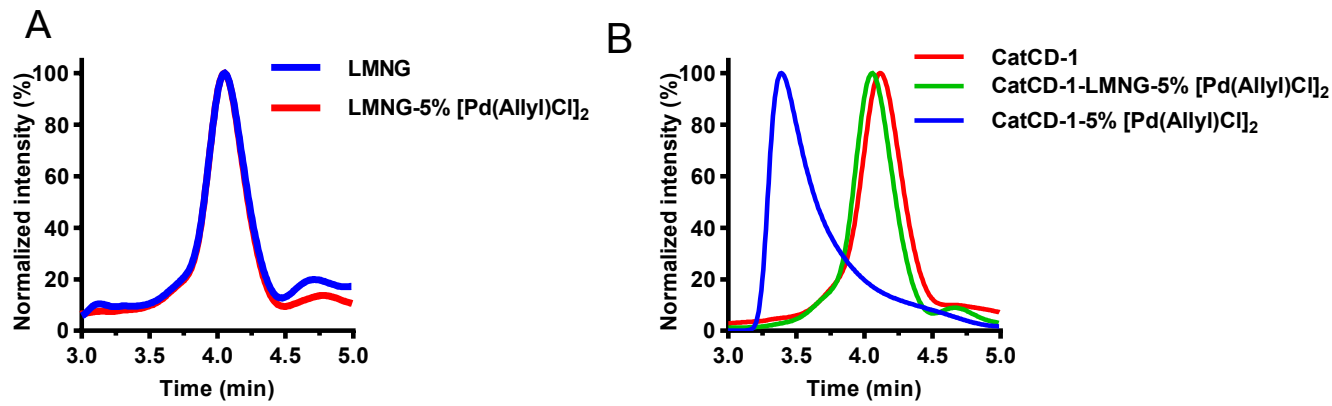

Figure S7. SEC-profiling of MsbA by the treatment of $[\mathrm{Pd}(\text { allyl }) \mathrm{Cl}]_{2}$. (A) MsbA (1 $\mathrm{mg} / \mathrm{mL}, 20 \mathrm{mM}$ HEPES 7.5, $100 \mathrm{mM} \mathrm{NaCl}, 0.005 \% \mathrm{w} / \mathrm{v} \mathrm{LMNG}$ ) remained intact after the treatment of $5 \%[\mathrm{Pd}(\text { allyl }) \mathrm{Cl}]_{2}$ at $4{ }^{\circ} \mathrm{C}$ for $8 \mathrm{~h}$. (B) MsbA solubilized in CatCD-1 was treated with $5 \%[\mathrm{Pd}(\text { allyl }) \mathrm{Cl}]_{2}$ with or without LMNG. 
A

- $\mathrm{CCD}-2$

- CCD-2 DDM TCEP

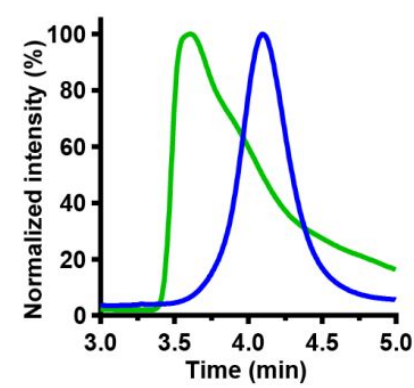

B

- CatCD-1

- CatCD-1 DDM Pd

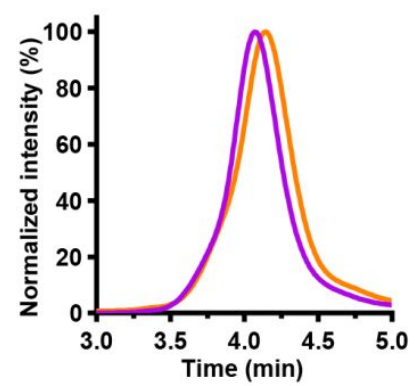

Figure S8. SEC profiling of MsbA before and after detergents exchanged in CCD-2 or CatCD-1. (A) MsbA was solubilized in CCD-2 (blue) and exchanged in DDM in the presence of TCEP (green). (B) MsbA was solubilized in CatCD-1 and exchanged in $\mathrm{DDM}$ in the presence of $[\mathrm{Pd}(\text { allyl }) \mathrm{Cl}]_{2}$. 
Table S2. Commercial detergents for reconstitution studies of MsbA.

\begin{tabular}{|c|c|c|c|c|}
\hline \multirow{2}{*}{ No. } & Name & MW & \multicolumn{2}{|c|}{ CMC } \\
\cline { 5 - 6 } & & & $\mathrm{mM}$ & $\%$ \\
\hline DDM & $n$-Dodecyl- $\beta$-D-Maltopyranoside & 510.6 & 0.17 & 0.0087 \\
\hline LMNG & Lauryl Maltose Neopentyl Glycol & 1005.2 & 0.01 & 0.0010 \\
\hline NG & $n$-Nonyl- $\beta$-D-Glucopyranoside & 306.4 & 6.5 & 0.2 \\
\hline LDAO & $n$-Dodecyl- $N, N$-Dimethylamine-N-Oxide & 229.4 & 2 & 0.05 \\
\hline CHAPS & CHAPS & 614.9 & 8 & 0.49 \\
\hline DM & $n$-Decyl- $\beta$-D-Maltopyranoside & 482.6 & 1.8 & 0.087 \\
\hline TX-100 & $n$ Triton X-100 & 646.9 & 0.9 & 0.058 \\
\hline UDM & $n$-Undecyl- $\beta$-D-Maltopyranoside & 496.6 & 0.59 & 0.029 \\
\hline
\end{tabular}




\section{General methods for synthetic chemistry}

Unless otherwise stated, all commercial reagents and solvents were used without additional purification. Chromatography was performed on silica gel 200-300 mesh. NMR spectra were recorded on a Bruker AVANCE III 500 or 800 spectrometer (FT, $500 / 800 \mathrm{MHz}$ for ${ }^{1} \mathrm{H} \mathrm{NMR} ; 126 / 201 \mathrm{MHz}$ for ${ }^{13} \mathrm{C} \mathrm{NMR}$ ) at $298 \mathrm{~K}$ with $\mathrm{CDCl}_{3}$ or $\mathrm{CD}_{3} \mathrm{OD}$ as the solvent and tetramethylsilane (TMS) as the internal standard at the room temperature, unless otherwise noted. Chemical shifts were quoted in parts per million referenced to the residual solvent peak. TMS resonance as $0.00 \mathrm{ppm}, \mathrm{CDCl}_{3}$ resonance as $7.26 \mathrm{ppm}$ and $\mathrm{CD}_{3} \mathrm{OD}$ as $3.31 \mathrm{ppm}$ in the ${ }^{1} \mathrm{H}$ spectrum, $\mathrm{CDCl}_{3}$ resonance as 77.16 ppm, or $\mathrm{CD}_{3} \mathrm{OD}$ as $49.00 \mathrm{ppm}$ in the ${ }^{13} \mathrm{C}$ spectrum. Coupling constants $J$, were reported in hertz (Hz). High-resolution mass spectra (HRMS) were recorded on an Agilent 6230 mass spectrometer using ESI (electrospray ionization). High pressure liquid chromatography (HPLC) analysis was performed at $32{ }^{\circ} \mathrm{C}$ with Shimadzu Prominence HPLC system composed of LC20A pump, and ELSD LT II evaporative light detector with an XSelect HSS T3 $5 \mu \mathrm{m}$ column (4.6×250 mm, PN: 186004793). Systems were run with solvents as follows: solvent $\mathrm{A}=\mathrm{ddH}_{2} \mathrm{O}$ containing $0.05 \%$ TFA, solvent $\mathrm{B}=\mathrm{MeCN}$ containing $0.05 \%$ TFA, flow rate: $1.0 \mathrm{~mL} / \mathrm{min}$. Method: hold $2 \mathrm{~min}$ at $10 \%$ B, start $10 \% \mathrm{~B}$ in a linear gradient to $90 \% \mathrm{~B}$ in $8 \mathrm{~min}$, hold $2.5 \mathrm{~min}$ at $90 \% \mathrm{~B}$, and then gradient to $10 \% \mathrm{~B}$ in $1 \mathrm{~min}$, hold $4.5 \mathrm{~min}$ at $10 \% \mathrm{~B}$, total run time: $18 \mathrm{~min}$. The purity was calculated as percentage peak area using absorbance at AD2. All final compounds showed a purity of $>99 \%$. 
Synthesis of CatCDs

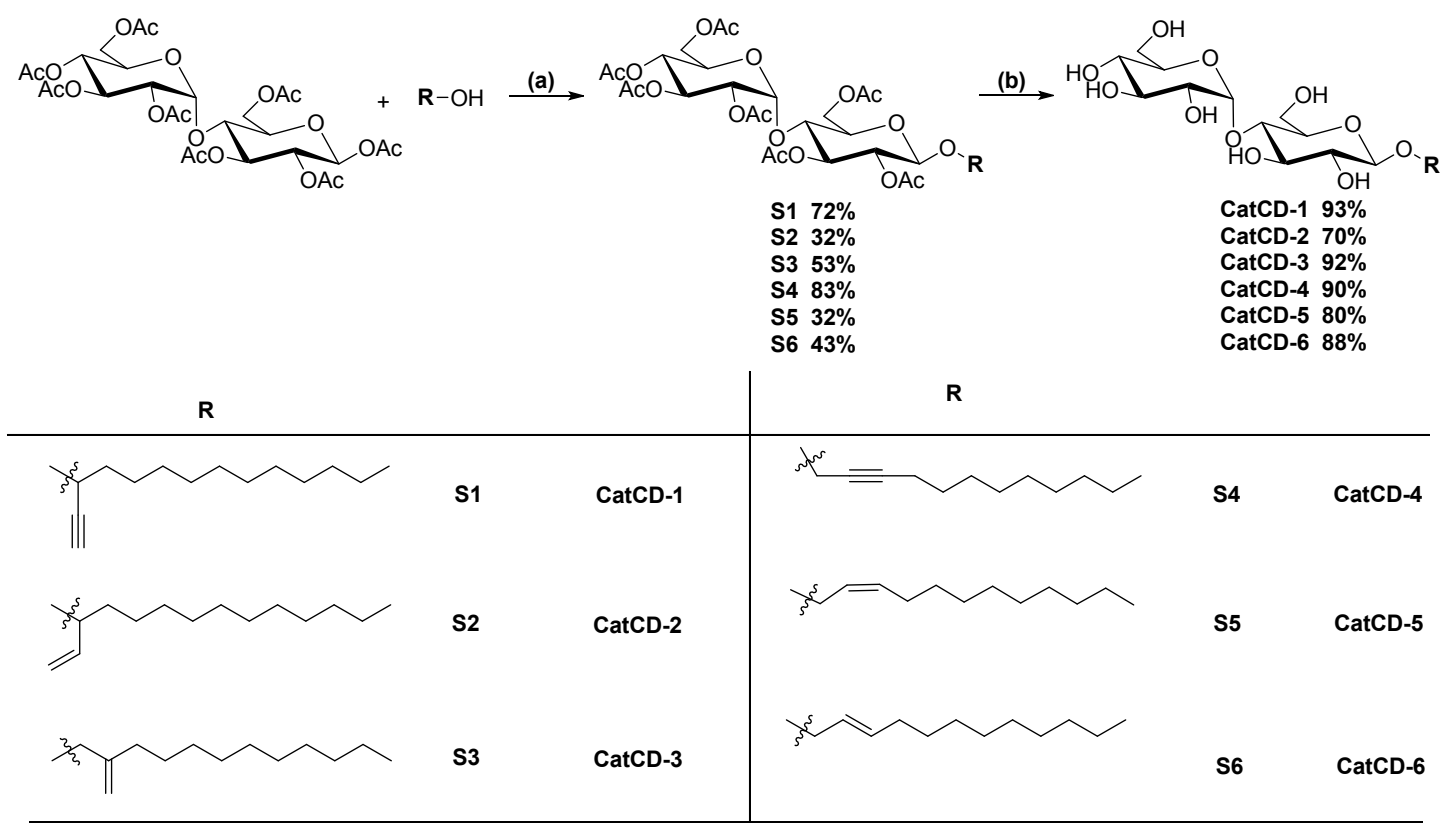

Scheme S1. Synthesis of CatCDs. Reagents and conditions: (a) $\mathrm{BF}_{3} \cdot \mathrm{Et}_{2} \mathrm{O}, \mathrm{CH}_{2} \mathrm{Cl}_{2}$, $0{ }^{\circ} \mathrm{C}$ to r.t., $4 \AA$ molecular sieve, 6 h. (b) $\mathrm{MeONa}, \mathrm{MeOH}$, r.t., 1 h. 


\section{General synthesis of glycosylation intermediates S1-S6.}

Known glycosyl acceptors were synthesized by following literature procedures. ${ }^{1-7} \mathrm{~A}$ mixture of octaacetyl- $\beta$-maltose (1.5 equiv.), glycosyl acceptors (1 equiv.) and $4 \AA$ molecular sieve in anhydrous $\mathrm{CH}_{2} \mathrm{Cl}_{2}$ under $\mathrm{N}_{2}$ was cooled to $0{ }^{\circ} \mathrm{C}$. To the reaction, $\mathrm{BF}_{3} \cdot \mathrm{Et}_{2} \mathrm{O}$ (1.7 equiv) was added dropwise over $20 \mathrm{~min}$. The reaction mixture was slowly warmed up to room temperature and stirred for $6 \mathrm{~h}$. The reaction was quenched by the addition of $\mathrm{NaHCO}_{3}$ solution and extracted three times with EtOAc. The organic layers were washed with brine, dried over $\mathrm{Na}_{2} \mathrm{SO}_{4}$ and filtered. The filtration was concentrated in vacuum and the crude was further purified by flash column chromatography on silica gel to obtain S1-S6.

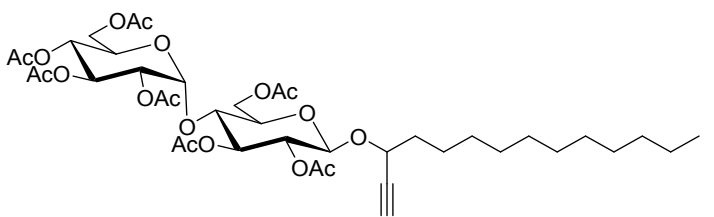

S1: white foam, $6.2 \mathrm{~g}, 72 \%$ yield, elution: hexanes/EtOAc (3:1); ${ }^{1} \mathrm{H}$ NMR (500 MHz, $\left.\mathrm{CDCl}_{3}\right) \delta 5.38(\mathrm{~d}, J=4.0 \mathrm{~Hz}, 1 \mathrm{H}), 5.33(\mathrm{t}, J=10.0 \mathrm{~Hz}, 1 \mathrm{H}), 5.29-5.20(\mathrm{~m}, 1 \mathrm{H}), 5.02$ $(\mathrm{td}, J=9.9,5.4 \mathrm{~Hz}, 1 \mathrm{H}), 4.88-4.70(\mathrm{~m}, 3 \mathrm{H}), 4.49-4.16(\mathrm{~m}, 4 \mathrm{H}), 4.05-3.89(\mathrm{~m}, 3 \mathrm{H})$, $3.72-3.65(\mathrm{~m}, 1 \mathrm{H}), 2.45(\mathrm{dd}, J=13.2,2.1 \mathrm{~Hz}, 1 \mathrm{H}), 2.15-1.93(\mathrm{~m}, 21 \mathrm{H}), 1.74-1.60$ $(\mathrm{m}, 2 \mathrm{H}), 1.42-1.31(\mathrm{~m}, 2 \mathrm{H}), 1.30-1.16(\mathrm{~m}, 16 \mathrm{H}), 0.85(\mathrm{t}, J=6.8 \mathrm{~Hz}, 3 \mathrm{H}) ;{ }^{13} \mathrm{C} \mathrm{NMR}$ $\left(126 \mathrm{MHz}, \mathrm{CDCl}_{3}\right) \delta 170.64,170.62,170.5,170.4,170.3,170.04,170.01,169.8,169.6$, $169.5,99.4,97.3,95.6,82.0,81.5,75.7,75.5,74.9,74.5,72.91,72.87,72.4,72.3,72.2$, $71.9,70.7,70.1,70.07,69.4,68.58,68.56,68.1,67.6,62.8,61.65,61.60,35.9,35.2$, 32.0, 29.71, 29.70, 29.62, 29.58, 29.56, 29.4, 29.2, 25.1, 24.7, 22.7, 21.0, 20.93, 20.90, 20.8, 20.69, 20.68, 20.65, 14.2; HRMS (ESI-TOF) $\mathrm{m} / \mathrm{z}:[\mathrm{M}+\mathrm{Na}]^{+}$calcd for $\mathrm{C}_{40} \mathrm{H}_{60} \mathrm{NaO}_{18}$ 851.3672; found: 851.3672.

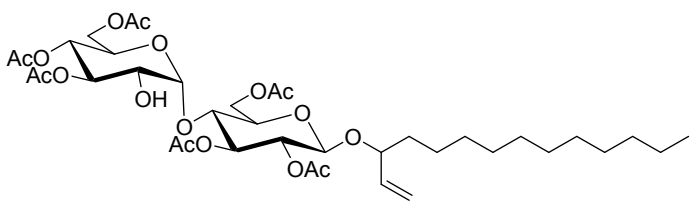


S2: white foam, $0.43 \mathrm{~g}, 32 \%$ yield, elution: hexanes/EtOAc $(3: 1) ;{ }^{1} \mathrm{H}$ NMR $(500 \mathrm{MHz}$, $\left.\mathrm{CDCl}_{3}\right) \delta 5.86-5.51(\mathrm{~m}, 1 \mathrm{H}), 5.40(\mathrm{~d}, J=3.8 \mathrm{~Hz}, 1 \mathrm{H}), 5.34(\mathrm{t}, J=10.0 \mathrm{~Hz}, 1 \mathrm{H}), 5.26$ $-5.17(\mathrm{~m}, 2 \mathrm{H}), 5.17-5.08(\mathrm{~m}, 1 \mathrm{H}), 5.04(\mathrm{td}, J=9.9,4.2 \mathrm{~Hz}, 1 \mathrm{H}), 4.89-4.80(\mathrm{~m}, 2 \mathrm{H})$, $4.56(\mathrm{t}, J=7.9 \mathrm{~Hz}, 1 \mathrm{H}), 4.46$ and $4.40(\mathrm{dd}, J=12.0,2.9 \mathrm{~Hz}, 1 \mathrm{H}), 4.30-4.16(\mathrm{~m}, 2 \mathrm{H})$, $4.14-3.90(\mathrm{~m}, 4 \mathrm{H}), 3.65-3.60(\mathrm{~m}, 1 \mathrm{H}), 2.20-1.94(\mathrm{~m}, 21 \mathrm{H}), 1.63-1.54(\mathrm{~m}, 2 \mathrm{H})$, $1.34-1.18(\mathrm{~m}, 19 \mathrm{H}), 0.86(\mathrm{t}, J=7.1 \mathrm{~Hz}, 3 \mathrm{H}) ;{ }^{13} \mathrm{C} \mathrm{NMR}\left(126 \mathrm{MHz}, \mathrm{CDCl}_{3}\right) \delta 170.81$, $170.76,170.5,170.3,170.1,169.7,169.5,140.1,140.0,131.0,129.0,122.1,122.0$, 115.2, 115.1, 97.0, 96.9, 95.6, 95.0, 77.4, 77.2, 76.9, 75.8, 75.5, 75.3, 73.7, 72.6, 72.3, $70.4,70.3,70.0,68.9,68.8,68.4,68.3,68.2,67.6,67.5,65.7,64.0,61.9,36.4,32.0$, $31.6,30.7,30.3,29.80,29.76,29.73,29.70,29.63,29.60,29.4,25.42,25.38,22.8$, 22.0, 21.8, 20.9, 20.81, 20.78, 20.7, 19.3, 14.2, 13.8; HRMS (ESI-TOF) m/z: [M + Na] ${ }^{+}$ calcd for $\mathrm{C}_{40} \mathrm{H}_{62} \mathrm{NaO} 18$ 853.3828; found: 853.3828.

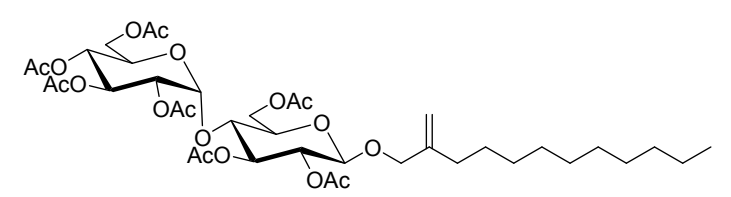

S3: white foam, $0.86 \mathrm{~g}, 53 \%$ yield, elution: hexanes/EtOAc (3:1); ${ }^{1} \mathrm{H}$ NMR (500 MHz, $\left.\mathrm{CDCl}_{3}\right) \delta 5.40(\mathrm{~d}, J=4.2 \mathrm{~Hz}, 1 \mathrm{H}), 5.34(\mathrm{t}, J=10.0 \mathrm{~Hz}, 1 \mathrm{H}), 5.24(\mathrm{t}, J=9.1 \mathrm{~Hz}, 1 \mathrm{H})$, $5.04(\mathrm{t}, J=9.9 \mathrm{~Hz}, 1 \mathrm{H}), 4.98-4.79(\mathrm{~m}, 4 \mathrm{H}), 4.57-4.35(\mathrm{~m}, 2 \mathrm{H}), 4.31-4.12(\mathrm{~m}, 3 \mathrm{H})$, $4.10-3.90(\mathrm{~m}, 4 \mathrm{H}), 3.69-3.61(\mathrm{~m}, 1 \mathrm{H}), 2.18-1.92(\mathrm{~m}, 21 \mathrm{H}), 1.46-1.36(\mathrm{~m}, 2 \mathrm{H})$, $1.34-1.14(\mathrm{~m}, 16 \mathrm{H}), 0.86(\mathrm{t}, J=6.9 \mathrm{~Hz}, 3 \mathrm{H}) ;{ }^{13} \mathrm{C} \mathrm{NMR}\left(126 \mathrm{MHz}, \mathrm{CDCl}_{3}\right) \delta 170.7$, $170.4,170.1,169.7,169.6,144.8,112.6,98.7,95.6,75.6,72.9,72.3,72.2,71.8,70.1$, $69.5,68.6,68.1,63.0,61.6,33.0,32.0,29.7,29.62,29.56,29.4,27.5,22.8,21.0,20.9$, 20.8, 20.74, 20.69, 14.2; HRMS (ESI-TOF) m/z: $[\mathrm{M}+\mathrm{Na}]^{+}$calcd for $\mathrm{C}_{39} \mathrm{H}_{60} \mathrm{NaO}_{18}$ 839.3672; found: 839.3672 .

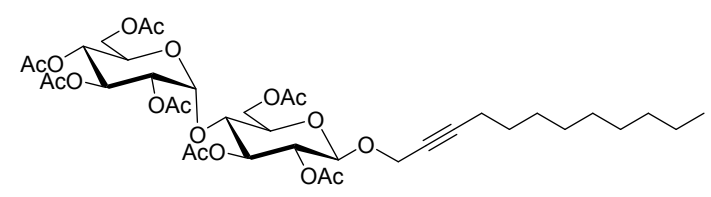

S4: white foam, $0.68 \mathrm{~g}, 83 \%$ yield, elution: hexanes/EtOAc (3:1); ${ }^{1} \mathrm{H}$ NMR (500 MHz, $\left.\mathrm{CDCl}_{3}\right) \delta 5.39(\mathrm{~d}, J=4.0 \mathrm{~Hz}, 1 \mathrm{H}), 5.37-5.31(\mathrm{~m}, 1 \mathrm{H}), 5.26(\mathrm{t}, J=9.0 \mathrm{~Hz}, 1 \mathrm{H}), 5.03$ 
(t, $J=9.9 \mathrm{~Hz}, 1 \mathrm{H}), 4.86-4.79(\mathrm{~m}, 2 \mathrm{H}), 4.77$ (d, $J=7.9 \mathrm{~Hz}, 1 \mathrm{H}), 4.47$ (dd, $J=12.1$, $2.8 \mathrm{~Hz}, 1 \mathrm{H}), 4.32-4.27(\mathrm{~m}, 2 \mathrm{H}), 4.26-4.19(\mathrm{~m}, 2 \mathrm{H}), 4.05-3.97(\mathrm{~m}, 2 \mathrm{H}), 3.96-3.91$ $(\mathrm{m}, 1 \mathrm{H}), 3.71-3.66(\mathrm{~m}, 1 \mathrm{H}), 2.23-2.16(\mathrm{~m}, 2 \mathrm{H}), 2.14-1.95(\mathrm{~m}, 21 \mathrm{H}), 1.49(\mathrm{p}, J=$ $7.2 \mathrm{~Hz}, 2 \mathrm{H}), 1.39-1.20(\mathrm{~m}, 13 \mathrm{H}), 0.86(\mathrm{t}, J=6.8 \mathrm{~Hz}, 3 \mathrm{H}) ;{ }^{13} \mathrm{C}$ NMR $(126 \mathrm{MHz}$, $\left.\mathrm{CDCl}_{3}\right) \delta 170.7,170.6,170.4,170.1,169.8,169.5,97.5,95.6,88.4,75.6,74.3,72.8$, $72.2,72.0,69.4,68.6,68.1,62.8,61.6,56.7,31.9,29.6,29.4,29.2,29.0,28.7,22.8$, 21.0, 20.9, 20.8, 20.70, 20.67, 18.8, 14.2; HRMS (ESI-TOF) $\mathrm{m} / \mathrm{z}:[\mathrm{M}+\mathrm{Na}]^{+}$calcd for $\mathrm{C}_{38} \mathrm{H}_{56} \mathrm{NaO}_{18}$ 823.3359; found: 823.3354.

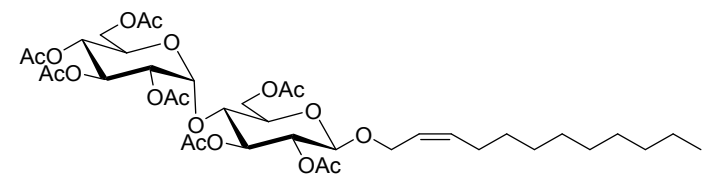

S5: white foam, $0.71 \mathrm{~g}, 32 \%$ yield, elution: hexanes/EtOAc (3:1); ${ }^{1} \mathrm{H}$ NMR (500 MHz, $\left.\mathrm{CDCl}_{3}\right) \delta 5.41(\mathrm{~d}, J=4.2 \mathrm{~Hz}, 1 \mathrm{H}), 5.36(\mathrm{t}, J=10.0 \mathrm{~Hz}, 1 \mathrm{H}), 5.25(\mathrm{t}, J=9.1 \mathrm{~Hz}, 1 \mathrm{H})$, $5.05(\mathrm{t}, J=9.9 \mathrm{~Hz}, 1 \mathrm{H}), 4.97(\mathrm{~s}, 1 \mathrm{H}), 4.91-4.82(\mathrm{~m}, 2 \mathrm{H}), 4.54(\mathrm{~d}, J=7.9 \mathrm{~Hz}, 1 \mathrm{H})$, $4.48(\mathrm{dd}, J=12.2,2.9 \mathrm{~Hz}, 1 \mathrm{H}), 4.34-4.18(\mathrm{~m}, 3 \mathrm{H}), 4.10-3.92(\mathrm{~m}, 4 \mathrm{H}), 3.70-3.64$ $(\mathrm{m}, 1 \mathrm{H}), 2.18-1.96(\mathrm{~m}, 21 \mathrm{H}), 1.47-1.34(\mathrm{~m}, 2 \mathrm{H}), 1.30-1.23(\mathrm{~m}, 14 \mathrm{H}), 0.88(\mathrm{t}, J=$ $6.9 \mathrm{~Hz}, 3 \mathrm{H}) ;{ }^{13} \mathrm{C} \mathrm{NMR}\left(126 \mathrm{MHz}, \mathrm{CDCl}_{3}\right) \delta 170.62,170.60,170.4,170.0,169.7,169.5$, $135.4,124.4,98.7,95.6,75.6,72.8,72.24,72.19,70.1,69.4,68.6,68.1,64.6,63.0,61.6$, 32.0, 29.63, 29.59, 29.4, 29.3, 27.6, 22.7, 21.0, 20.9, 20.8, 20.7, 20.6, 14.2; HRMS (ESI-TOF) m/z: $\left[\mathrm{M}+\mathrm{NH}_{4}\right]^{+}$calcd for $\mathrm{C}_{38} \mathrm{H}_{62} \mathrm{NO}_{18}$ 820.3961; found: 820.3967 .

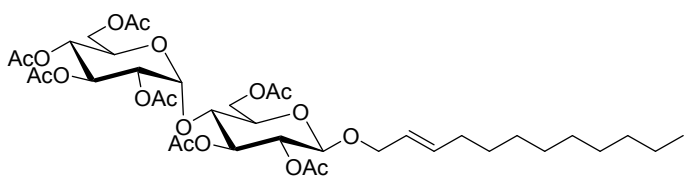

S6: white foam, $0.94 \mathrm{~g}, 43 \%$ yield, elution: hexanes/EtOAc (3:1); ${ }^{1} \mathrm{H}$ NMR (500 MHz, $\left.\mathrm{CDCl}_{3}\right) \delta 5.69-5.63(\mathrm{~m}, 1 \mathrm{H}), 5.58-5.40(\mathrm{~m}, 1 \mathrm{H}), 5.38(\mathrm{~d}, J=4.0 \mathrm{~Hz}, 1 \mathrm{H}), 5.35-$ $5.30(\mathrm{~m}, 1 \mathrm{H}), 5.22(\mathrm{t}, J=9.1 \mathrm{~Hz}, 1 \mathrm{H}), 5.02(\mathrm{t}, J=10.0 \mathrm{~Hz}, 1 \mathrm{H}), 4.85-4.79(\mathrm{~m}, 2 \mathrm{H})$, $4.55(\mathrm{~d}, J=7.9 \mathrm{~Hz}, 1 \mathrm{H}), 4.44(\mathrm{dd}, J=12.1,2.8 \mathrm{~Hz}, 1 \mathrm{H}), 4.21(\mathrm{td}, J=12.0,4.3 \mathrm{~Hz}, 3 \mathrm{H})$, $4.03-3.92(\mathrm{~m}, 4 \mathrm{H}), 3.66-3.61(\mathrm{~m}, 1 \mathrm{H}), 2.15-2.12(\mathrm{~m}, 2 \mathrm{H}), 2.11-1.85(\mathrm{~m}, 21 \mathrm{H})$, $1.39-1.30(\mathrm{~m}, 2 \mathrm{H}), 1.29-1.18(\mathrm{~m}, 13 \mathrm{H}), 0.85(\mathrm{t}, J=7.0 \mathrm{~Hz}, 3 \mathrm{H}) ;{ }^{13} \mathrm{C}$ NMR $(126$ 
$\left.\mathrm{MHz}, \mathrm{CDCl}_{3}\right) \delta 170.69,170.68,170.65,170.4,170.1,169.8,169.6,136.2,124.7,98.7$, $95.6,75.7,72.8,72.3,72.1,70.15,70.09,69.4,68.6,68.1,63.0,61.6,60.5,32.4,32.0$, 29.7, 29.6, 29.4, 29.3 29.1 22.8, 21.05, 21.00, 20.8, 20.74, 20.71, 20.69, 14.2; HRMS (ESI-TOF) m/z: [M+Na $]^{+}$calcd for $\mathrm{C}_{38} \mathrm{H}_{58} \mathrm{NaO}_{18}$ 825.3515; found: 825.3515.

\section{General synthesis of CatCDs.}

To a solution of S1-S6 (1 equiv.) in $\mathrm{MeOH}$ was added $\mathrm{MeONa}(5 \mathrm{M}$ in $\mathrm{MeOH}, 0.5$ equiv.). The reaction was stirred at room temperature for $1 \mathrm{~h}$. After that, the reaction was neutralized with Amberlite IR120 H form ion-exchange resin. The reaction was filtered and concentrated in vacuum. The filtration was concentrated in vacuum and the crude was further purified by flash column chromatography on silica gel to obtain

\section{CatCDs.}

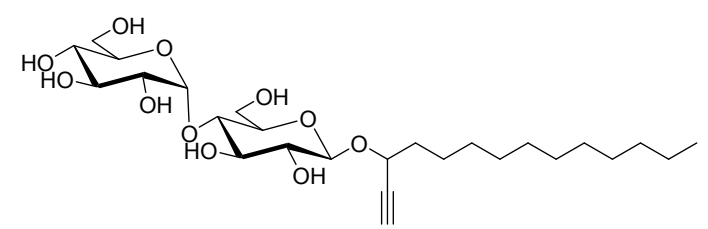

CatCD-1: white foam, $3.5 \mathrm{~g}, 93 \%$ yield, elution: $\mathrm{CH}_{2} \mathrm{Cl}_{2} / \mathrm{CH}_{3} \mathrm{OH}$ (7:1); ${ }^{1} \mathrm{H}$ NMR (800 $\left.\mathrm{MHz}, \mathrm{CD}_{3} \mathrm{OD}\right) \delta 5.22(\mathrm{~d}, J=3.8 \mathrm{~Hz}, 1 \mathrm{H}), 4.70-4.64(\mathrm{~m}, 1 \mathrm{H}), 4.53-4.48(\mathrm{~m}, 1 \mathrm{H})$, $3.95-3.90(\mathrm{~m}, 1 \mathrm{H}), 3.89-3.83(\mathrm{~m}, 2 \mathrm{H}), 3.75-3.64(\mathrm{~m}, 4 \mathrm{H}), 3.62-3.58(\mathrm{~m}, 1 \mathrm{H})$, $3.51-3.48(\mathrm{~m}, 1 \mathrm{H}), 3.44-3.41(\mathrm{~m}, 1 \mathrm{H}), 3.31(\mathrm{td}, J=11.1,6.0 \mathrm{~Hz}, 2 \mathrm{H}), 2.91(\mathrm{dd}, J=$ 12.5, $2.1 \mathrm{~Hz}, 1 \mathrm{H}), 1.85-1.73(\mathrm{~m}, 2 \mathrm{H}), 1.56-1.50(\mathrm{~m}, 2 \mathrm{H}), 1.39-1.29(\mathrm{~m}, 16 \mathrm{H}), 0.94$ $(\mathrm{t}, J=7.1 \mathrm{~Hz}, 3 \mathrm{H}) ;{ }^{13} \mathrm{C}$ NMR $\left(201 \mathrm{MHz}, \mathrm{CD}_{3} \mathrm{OD}\right) \delta 103.0,102.8,102.7,100.8,84.0$, 83.0, 81.1, 80.9, 77.74, 77.71, 76.6, 76.0, 75.2, 75.0, 74.7, 74.6, 74.4, 74.0, 71.4, 70.6, $67.9,62.7,62.12,62.09,36.6,36.4,33.0,30.72,30.70,30.65,30.64,30.62,30.42$, 30.40, 26.2, 25.9, 23.7, 14.4; HRMS (ESI-TOF) m/z: [M+ Na $]^{+}$calcd for $\mathrm{C}_{26} \mathrm{H}_{46} \mathrm{NaO}_{11}$ 557.2932; found: 557.2933.

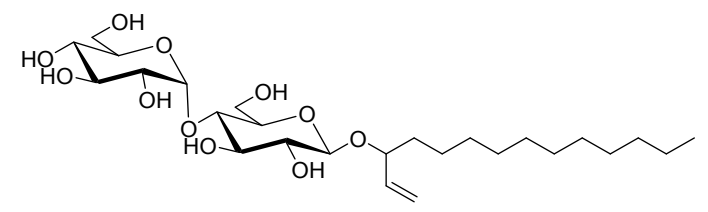


CatCD-2: white foam, $0.13 \mathrm{~g}, 70 \%$ yield, elution: $\mathrm{CH}_{2} \mathrm{Cl}_{2} / \mathrm{CH}_{3} \mathrm{OH}(7: 1) ;{ }^{1} \mathrm{H} \mathrm{NMR}$ (500 $\left.\mathrm{MHz}, \mathrm{CD}_{3} \mathrm{OD}\right) \delta 5.95-5.67(\mathrm{~m}, 1 \mathrm{H}), 5.30-5.23(\mathrm{~m}, 1 \mathrm{H}), 5.22-5.09(\mathrm{~m}, 2 \mathrm{H}), 4.38-$ $4.35(\mathrm{~m}, 1 \mathrm{H}), 4.28-4.10(\mathrm{~m}, 1 \mathrm{H}), 3.93-3.79(\mathrm{~m}, 3 \mathrm{H}), 3.74-3.67(\mathrm{~m}, 2 \mathrm{H}), 3.66-$ $3.60(\mathrm{~m}, 2 \mathrm{H}), 3.59-3.53(\mathrm{~m}, 1 \mathrm{H}), 3.47(\mathrm{dd}, J=9.7,3.8 \mathrm{~Hz}, 1 \mathrm{H}), 3.36-3.25(\mathrm{~m}, 3 \mathrm{H})$, $1.74-1.49(\mathrm{~m}, 2 \mathrm{H}), 1.41-1.26(\mathrm{~m}, 18 \mathrm{H}), 0.93(\mathrm{t}, J=6.9 \mathrm{~Hz}, 3 \mathrm{H}) ;{ }^{13} \mathrm{C}$ NMR $(126$ $\left.\mathrm{MHz}, \mathrm{CD}_{3} \mathrm{OD}\right) \delta 141.0,139.5,118.6,116.0,103.1,102.83,102.79,100.6,82.9,81.4$, $81.1,79.9,77.9,76.5,76.4,75.0,74.8,74.7,74.6,74.1,71.5,62.7,62.2,62.1,36.5$, 35.6, 33.0, 30.8, 30.72, 30.68, 30.4, 26.3, 25.9, 23.7, 14.4; HRMS (ESI-TOF) m/z: [M $+\mathrm{Na}]^{+}$calcd for $\mathrm{C}_{26} \mathrm{H}_{48} \mathrm{NaO}_{11}$ 559.3089; found: 559.3092 .

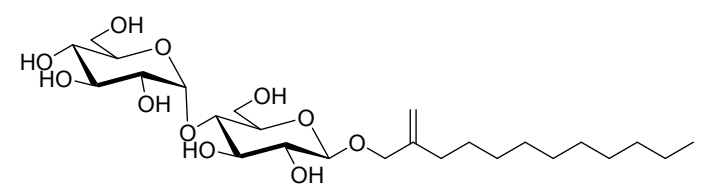

CatCD-3: white foam, $0.43 \mathrm{~g}, 92 \%$ yield, elution: $\mathrm{CH}_{2} \mathrm{Cl}_{2} / \mathrm{CH}_{3} \mathrm{OH}(7: 1) ;{ }^{1} \mathrm{H} \mathrm{NMR}$ $\left(500 \mathrm{MHz}, \mathrm{CD}_{3} \mathrm{OD}\right) \delta 5.14(\mathrm{~d}, J=3.8 \mathrm{~Hz}, 1 \mathrm{H}), 5.08-5.04(\mathrm{~m}, 1 \mathrm{H}), 4.31-4.25(\mathrm{~m}$, 2H), $4.06(\mathrm{~d}, J=12.7 \mathrm{~Hz}, 1 \mathrm{H}), 3.90-3.84(\mathrm{~m}, 1 \mathrm{H}), 3.83-3.76(\mathrm{~m}, 2 \mathrm{H}), 3.66(\mathrm{q}, J=$ $8.3 \mathrm{~Hz}, 2 \mathrm{H}), 3.59(\mathrm{td}, J=9.2,3.4 \mathrm{~Hz}, 3 \mathrm{H}), 3.52(\mathrm{t}, J=9.2 \mathrm{~Hz}, 1 \mathrm{H}), 3.42(\mathrm{dd}, J=9.7$, $3.8 \mathrm{~Hz}, 1 \mathrm{H}), 3.36-3.27(\mathrm{~m}, 3 \mathrm{H}), 3.28-3.21(\mathrm{~m}, 2 \mathrm{H}), 2.12-2.06(\mathrm{~m}, 2 \mathrm{H}), 1.49-1.40$ $(\mathrm{m}, 2 \mathrm{H}), 1.33-1.22(\mathrm{~m}, 15 \mathrm{H}), 0.88(\mathrm{t}, J=6.9 \mathrm{~Hz}, 3 \mathrm{H}) ;{ }^{13} \mathrm{C} \mathrm{NMR}\left(126 \mathrm{MHz}, \mathrm{CD}_{3} \mathrm{OD}\right)$ $\delta 147.1,112.2,103.1,102.9,81.3,77.8,76.6,75.0,74.8,74.6,74.1,72.5,71.5,62.7$, 62.2, 34.1, 33.1, 30.79, 30.75, 30.7, 30.53, 30.48, 28.7, 23.7, 14.5; HRMS (ESI-TOF) $\mathrm{m} / \mathrm{z}:[\mathrm{M}+\mathrm{Na}]^{+}$calcd for $\mathrm{C}_{25} \mathrm{H}_{46} \mathrm{NaO}_{11}$ 545.2932; found: 545.2936.

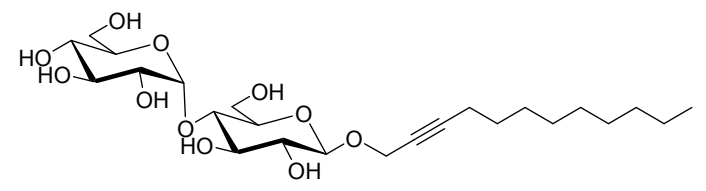

CatCD-4: white foam, $0.23 \mathrm{~g}, 90 \%$ yield, elution: $\mathrm{CH}_{2} \mathrm{Cl}_{2} / \mathrm{CH}_{3} \mathrm{OH}(7: 1) ;{ }^{1} \mathrm{H} \mathrm{NMR}$ $\left(800 \mathrm{MHz}, \mathrm{CD}_{3} \mathrm{OD}\right) \delta 5.21(\mathrm{~d}, J=3.9 \mathrm{~Hz}, 1 \mathrm{H}), 4.51(\mathrm{~d}, J=7.8 \mathrm{~Hz}, 1 \mathrm{H}), 4.46(\mathrm{dt}, J=$ 15.2, $2.2 \mathrm{~Hz}, 1 \mathrm{H}), 4.40$ (dt, $J=15.2,2.2 \mathrm{~Hz}, 1 \mathrm{H}), 3.92(\mathrm{dd}, J=12.2,2.1 \mathrm{~Hz}, 1 \mathrm{H}), 3.88$ $-3.83(\mathrm{~m}, 2 \mathrm{H}), 3.73-3.70(\mathrm{~m}, 2 \mathrm{H}), 3.69-3.64(\mathrm{~m}, 2 \mathrm{H}), 3.58(\mathrm{t}, J=9.3 \mathrm{~Hz}, 1 \mathrm{H}), 3.51$ $-3.48(\mathrm{~m}, 1 \mathrm{H}), 3.42-3.39(\mathrm{~m}, 1 \mathrm{H}), 3.34-3.28(\mathrm{~m}, 2 \mathrm{H}), 2.27-2.24(\mathrm{~m}, 2 \mathrm{H}), 1.53(\mathrm{p}$, 
$J=7.1 \mathrm{~Hz}, 2 \mathrm{H}), 1.46-1.41(\mathrm{~m}, 2 \mathrm{H}), 1.38-1.29(\mathrm{~m}, 11 \mathrm{H}), 0.94(\mathrm{t}, J=7.1 \mathrm{~Hz}, 3 \mathrm{H})$; ${ }^{13} \mathrm{C}$ NMR (201 MHz, CD 3 OD) $\delta 102.8,101.9,88.2,81.1,77.7,76.6,76.3,75.0,74.7$, $74.4,74.0,71.4,62.7,62.1,57.2,33.0,30.6,30.4,30.2,29.9,29.7,23.7,19.4,14.5$; HRMS (ESI-TOF) m/z: [M+ $\left.\mathrm{NH}_{4}\right]+$ calcd for $\mathrm{C}_{24} \mathrm{H}_{46} \mathrm{NO}_{11}$ 524.3065; found: 524.3068 .

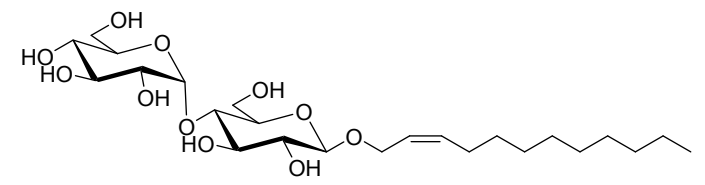

CatCD-5: white foam, $0.34 \mathrm{~g}, 80 \%$ yield, elution: $\mathrm{CH}_{2} \mathrm{Cl}_{2} / \mathrm{CH}_{3} \mathrm{OH}(7: 1)$; ${ }^{1} \mathrm{H}$ NMR (500 $\left.\mathrm{MHz}, \mathrm{CD}_{3} \mathrm{OD}\right) \delta 5.59-5.51(\mathrm{~m}, 2 \mathrm{H}), 5.12(\mathrm{~d}, J=3.8 \mathrm{~Hz}, 1 \mathrm{H}), 4.34(\mathrm{dd}, J=12.4,5.4$ Hz, 1H), $4.29-4.22(\mathrm{~m}, 2 \mathrm{H}), 3.85(\mathrm{~d}, J=13.3 \mathrm{~Hz}, 1 \mathrm{H}), 3.80-3.76(\mathrm{~m}, 2 \mathrm{H}), 3.67-$ $3.61(\mathrm{~m}, 2 \mathrm{H}), 3.57(\mathrm{t}, J=8.9 \mathrm{~Hz}, 2 \mathrm{H}), 3.51(\mathrm{t}, J=9.2 \mathrm{~Hz}, 1 \mathrm{H}), 3.41(\mathrm{dd}, J=9.7,3.7$ $\mathrm{Hz}, 1 \mathrm{H}), 3.33-3.29(\mathrm{~m}, 1 \mathrm{H}), 3.28-3.26(\mathrm{~m}, 2 \mathrm{H}), 3.26-3.17(\mathrm{~m}, 2 \mathrm{H}), 2.06(\mathrm{q}, J=6.9$ $\mathrm{Hz}, 2 \mathrm{H}), 1.37-1.31(\mathrm{~m}, 2 \mathrm{H}), 1.30-1.22(\mathrm{~m}, 12 \mathrm{H}), 0.87(\mathrm{t}, J=6.9 \mathrm{~Hz}, 3 \mathrm{H}) ;{ }^{13} \mathrm{C} \mathrm{NMR}$ $\left(126 \mathrm{MHz}, \mathrm{CD}_{3} \mathrm{OD}\right) \delta 134.9,126.7,103.0,102.9,81.3,77.8,76.6,75.0,74.8,74.6$, $74.1,71.4,65.6,62.7,62.1,33.1,30.73,30.67,30.64,30.5,30.4,28.5,23.7,14.5$; HRMS (ESI-TOF) m/z: [M + Na $]^{+}$calcd for $\mathrm{C}_{24} \mathrm{H}_{44} \mathrm{NaO}_{11}$ 531.2776; found: 531.2777.

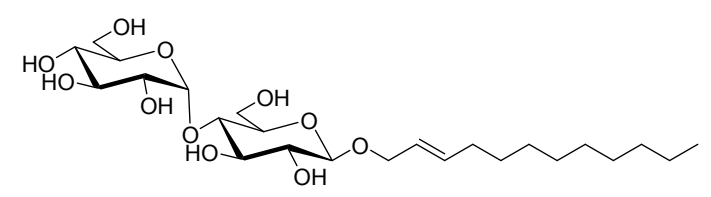

CatCD-6: white foam, $0.41 \mathrm{~g}, 88 \%$ yield, elution: $\mathrm{CH}_{2} \mathrm{Cl}_{2} / \mathrm{CH}_{3} \mathrm{OH}(7: 1) ;{ }^{1} \mathrm{H}$ NMR (500 $\left.\mathrm{MHz}, \mathrm{CD}_{3} \mathrm{OD}\right) \delta 5.82-5.73(\mathrm{~m}, 1 \mathrm{H}), 5.66-5.57(\mathrm{~m}, 1 \mathrm{H}), 5.19(\mathrm{~d}, J=3.8 \mathrm{~Hz}, 1 \mathrm{H})$, $4.39-4.30(\mathrm{~m}, 2 \mathrm{H}), 4.12(\mathrm{dd}, J=11.9,6.6 \mathrm{~Hz}, 1 \mathrm{H}), 3.91(\mathrm{~d}, J=12.2 \mathrm{~Hz}, 1 \mathrm{H}), 3.88-$ $3.80(\mathrm{~m}, 2 \mathrm{H}), 3.74-3.67(\mathrm{~m}, 2 \mathrm{H}), 3.66-3.60(\mathrm{~m}, 2 \mathrm{H}), 3.56(\mathrm{t}, J=9.2 \mathrm{~Hz}, 1 \mathrm{H}), 3.47$ $(\mathrm{dd}, J=9.8,3.6 \mathrm{~Hz}, 1 \mathrm{H}), 3.40-3.34(\mathrm{~m}, 1 \mathrm{H}), 3.34$ (d, $J=2.4 \mathrm{~Hz}, 1 \mathrm{H}), 3.33-3.24(\mathrm{~m}$, 2H), $2.08(\mathrm{q}, J=6.1 \mathrm{~Hz}, 2 \mathrm{H}), 1.41(\mathrm{~d}, J=6.3 \mathrm{~Hz}, 2 \mathrm{H}), 1.38-1.27(\mathrm{~m}, 13 \mathrm{H}), 0.92(\mathrm{t}, J$ $=6.8 \mathrm{~Hz}, 3 \mathrm{H}) ;{ }^{13} \mathrm{C} \mathrm{NMR}\left(126 \mathrm{MHz}, \mathrm{CD}_{3} \mathrm{OD}\right) \delta 136.1,127.1,102.93,102.85,81.2$, 77.8, 76.5, 75.0, 74.7, 74.6, 74.1, 71.4, 70.9, 62.7, 62.1, 33.3, 33.0, 30.7, 30.6, 30.4, 30.2, 23.7, 14.4; HRMS (ESI-TOF) m/z: $[\mathrm{M}+\mathrm{Na}]^{+}$calcd for $\mathrm{C}_{24} \mathrm{H}_{44} \mathrm{NaO}_{11}$ 531.2776; found: 531.2777 . 
NMR spectra of final CatCDs

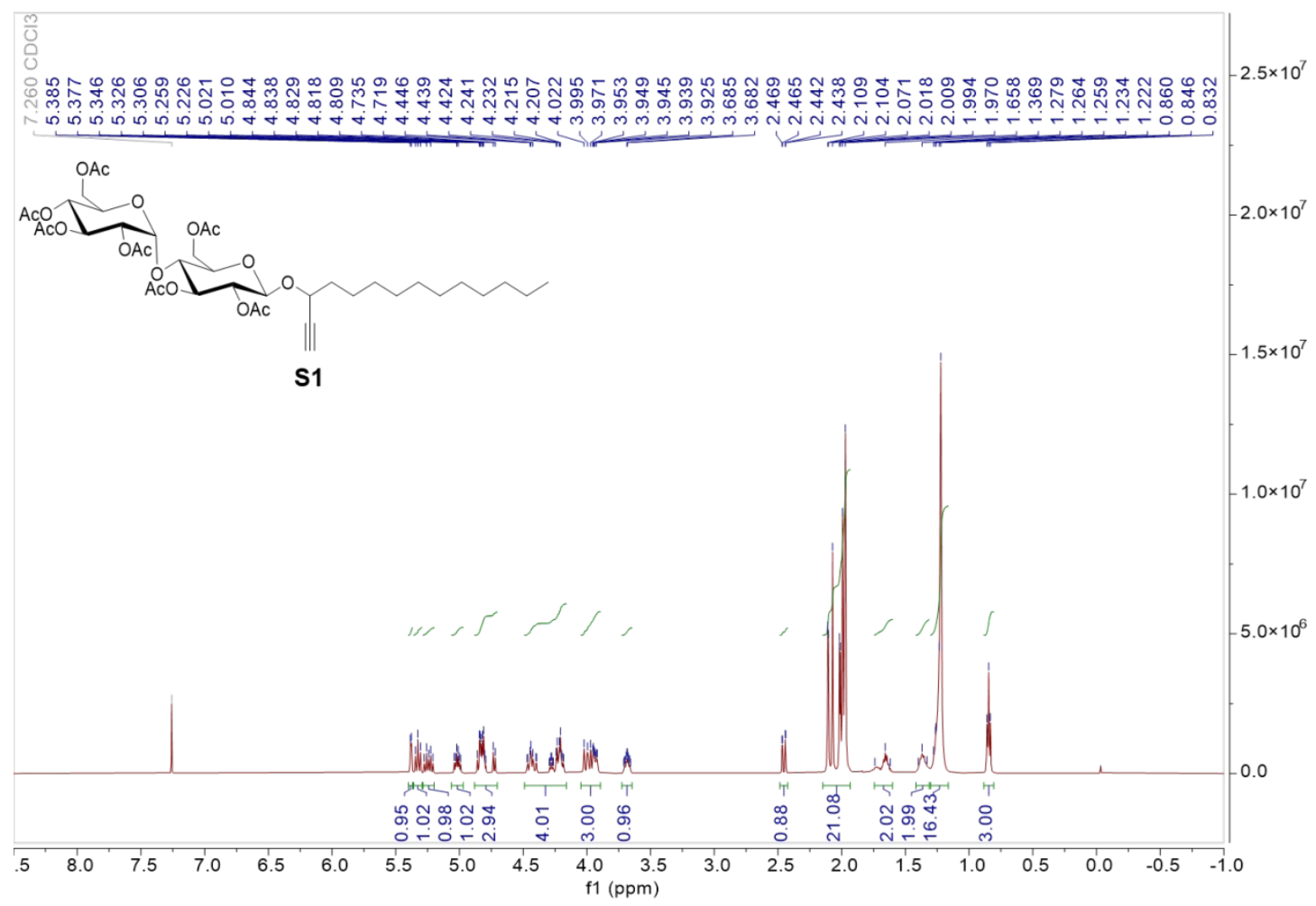

${ }^{1} \mathrm{H} \mathrm{NMR}$ of $\mathbf{S 1}\left(\mathrm{CDCl}_{3}, 500 \mathrm{MHz}\right)$

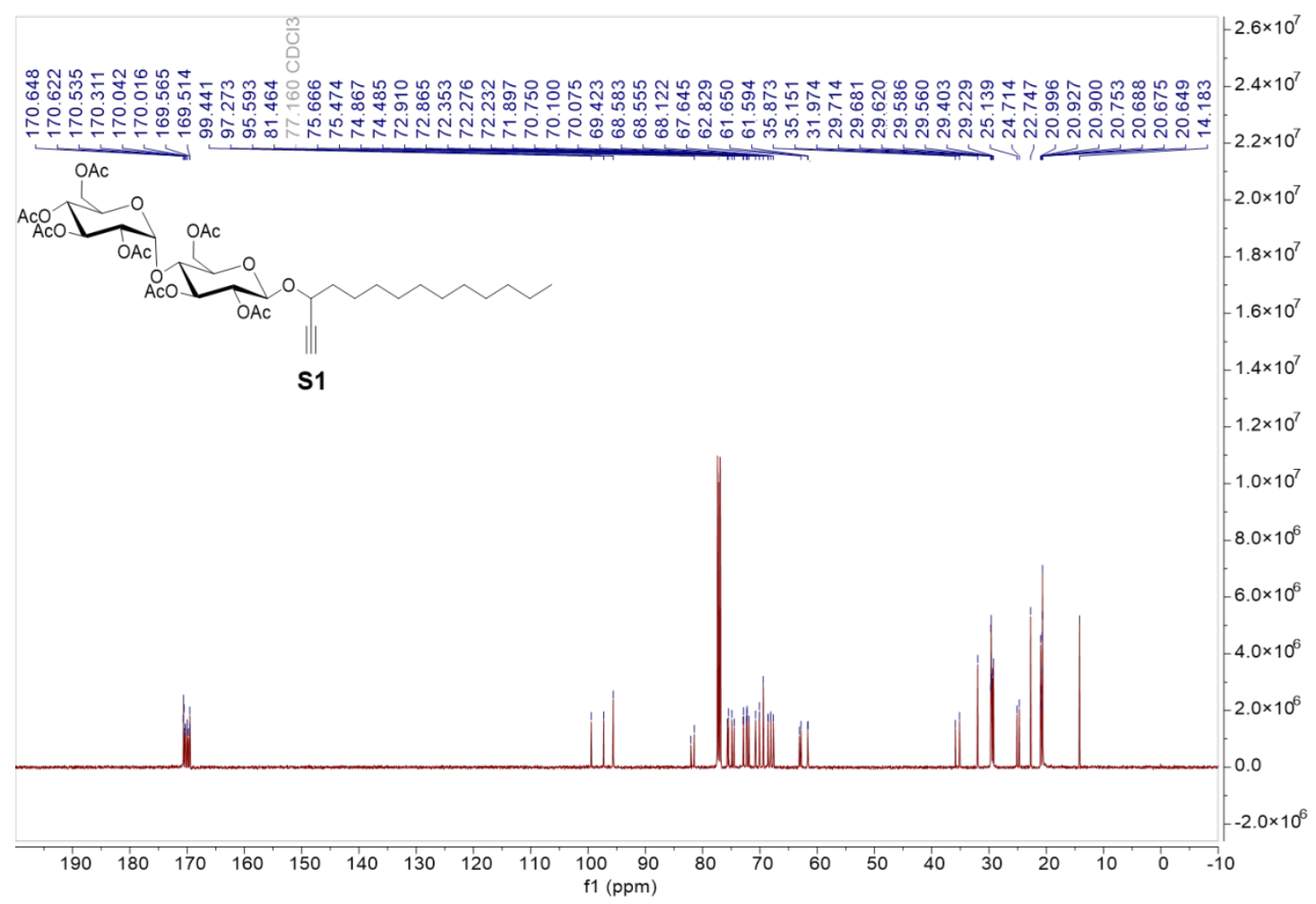

${ }^{13} \mathrm{C} \mathrm{NMR}$ of $\mathbf{S 1}\left(\mathrm{CDCl}_{3}, 126 \mathrm{MHz}\right)$ 


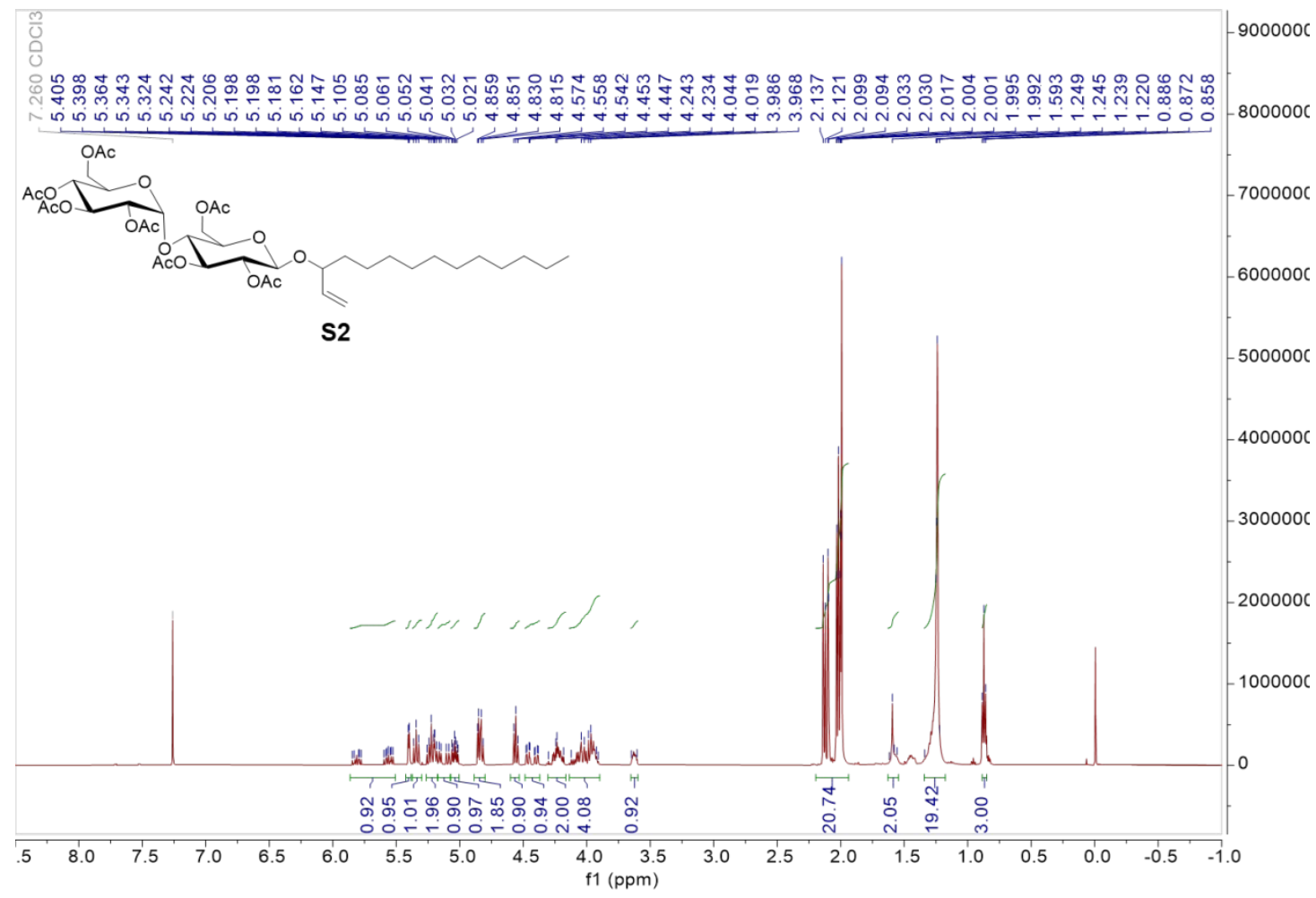

${ }^{1} \mathrm{H}$ NMR of $\mathbf{S} 2\left(\mathrm{CDCl}_{3}, 500 \mathrm{MHz}\right)$

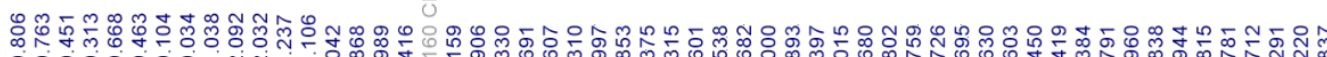

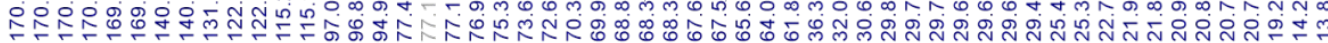

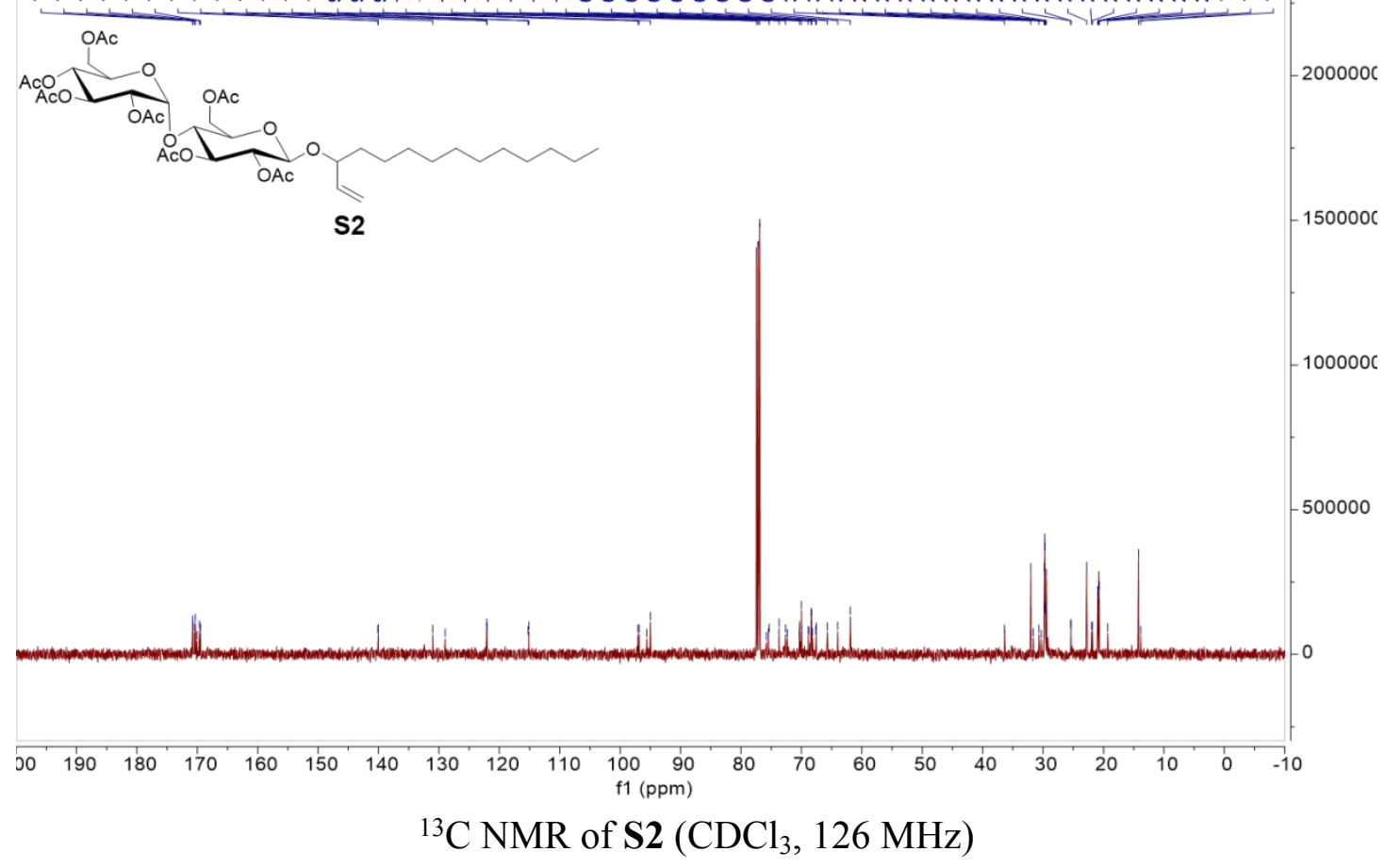




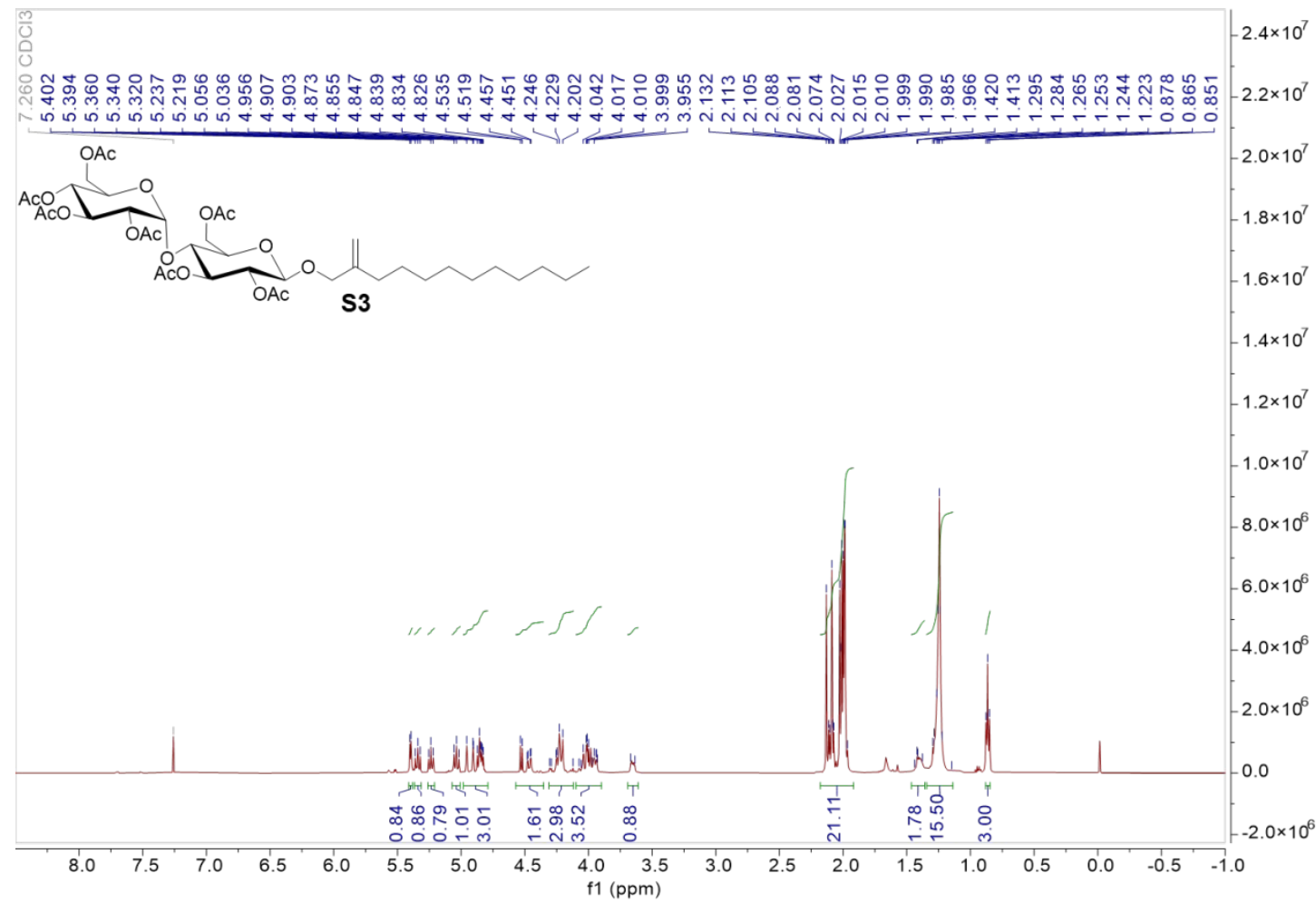

${ }^{1} \mathrm{H}$ NMR of $\mathbf{S 3}\left(\mathrm{CDCl}_{3}, 500 \mathrm{MHz}\right)$

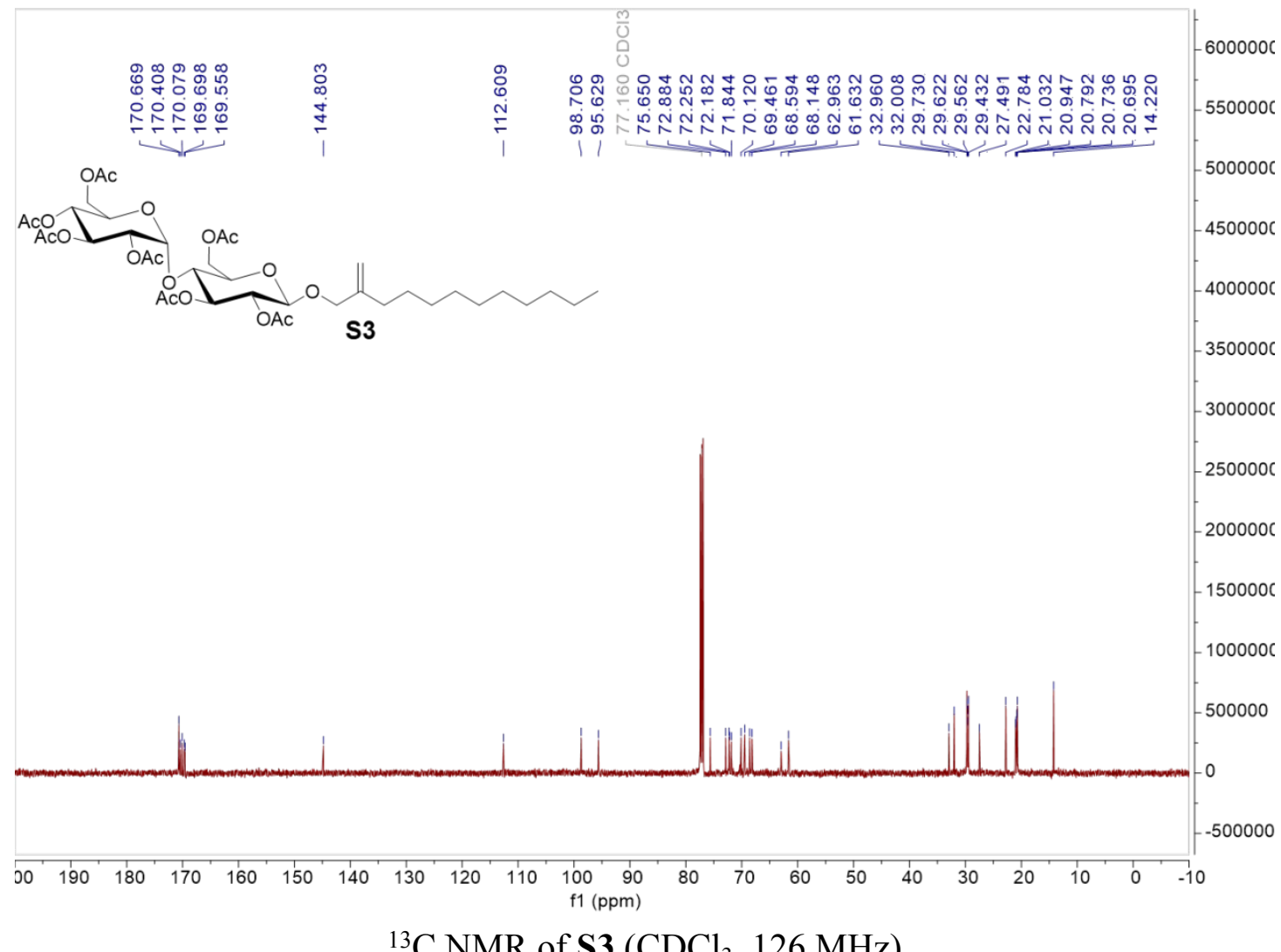

${ }^{13} \mathrm{C} \mathrm{NMR}$ of $\mathbf{S 3}\left(\mathrm{CDCl}_{3}, 126 \mathrm{MHz}\right)$ 


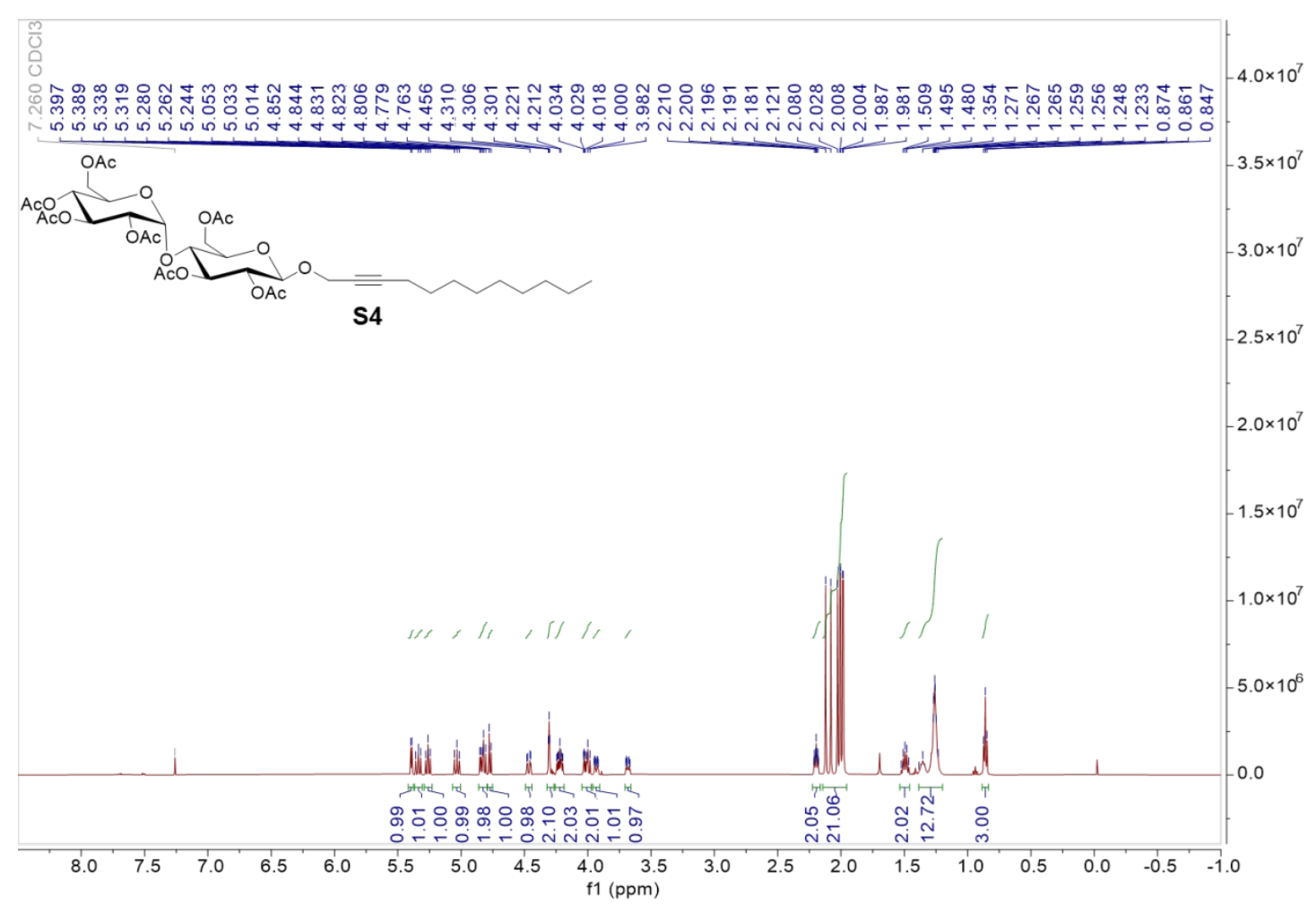

${ }^{1} \mathrm{H} \mathrm{NMR}$ of $\mathbf{S 4}\left(\mathrm{CDCl}_{3}, 500 \mathrm{MHz}\right)$

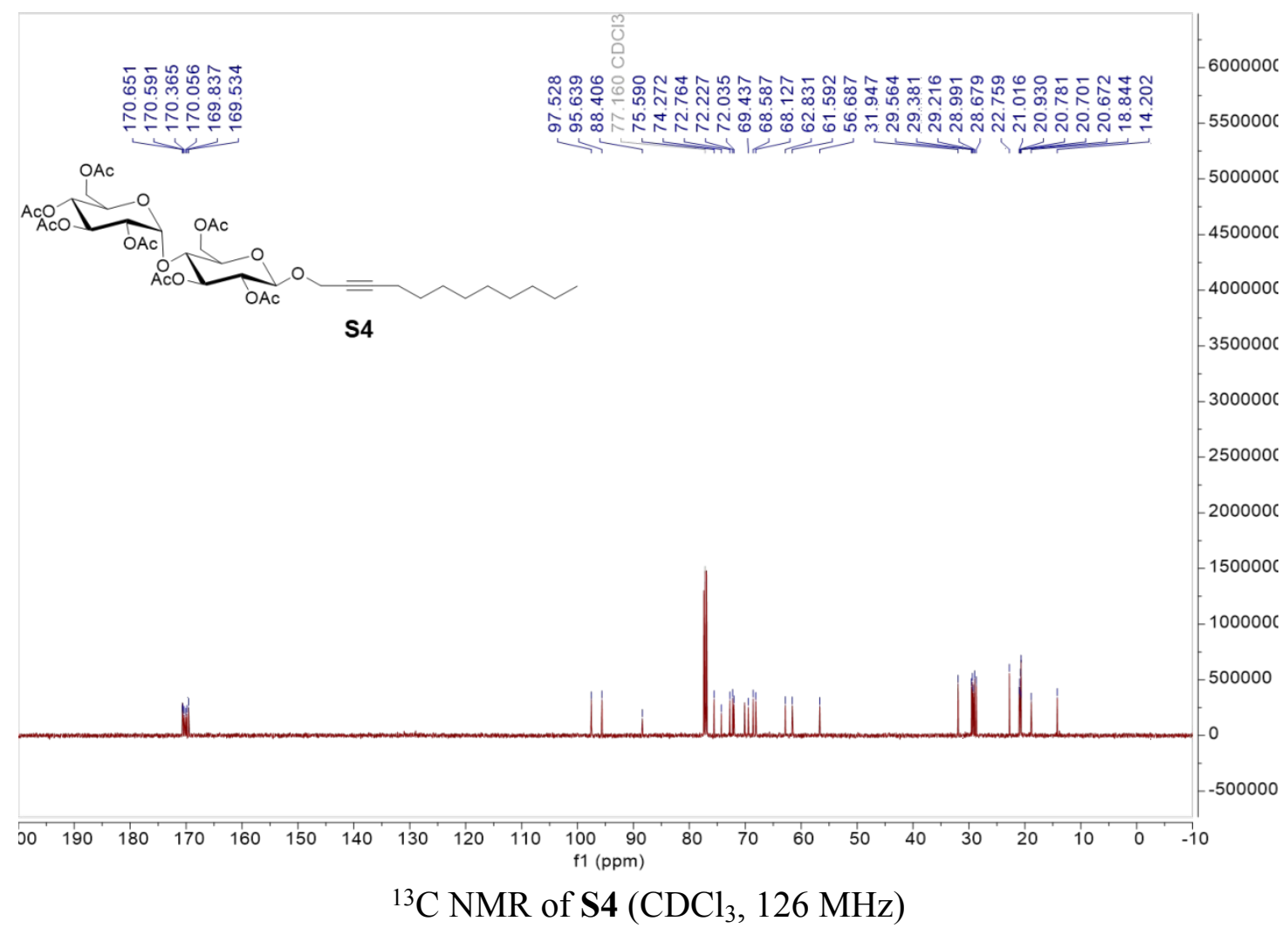




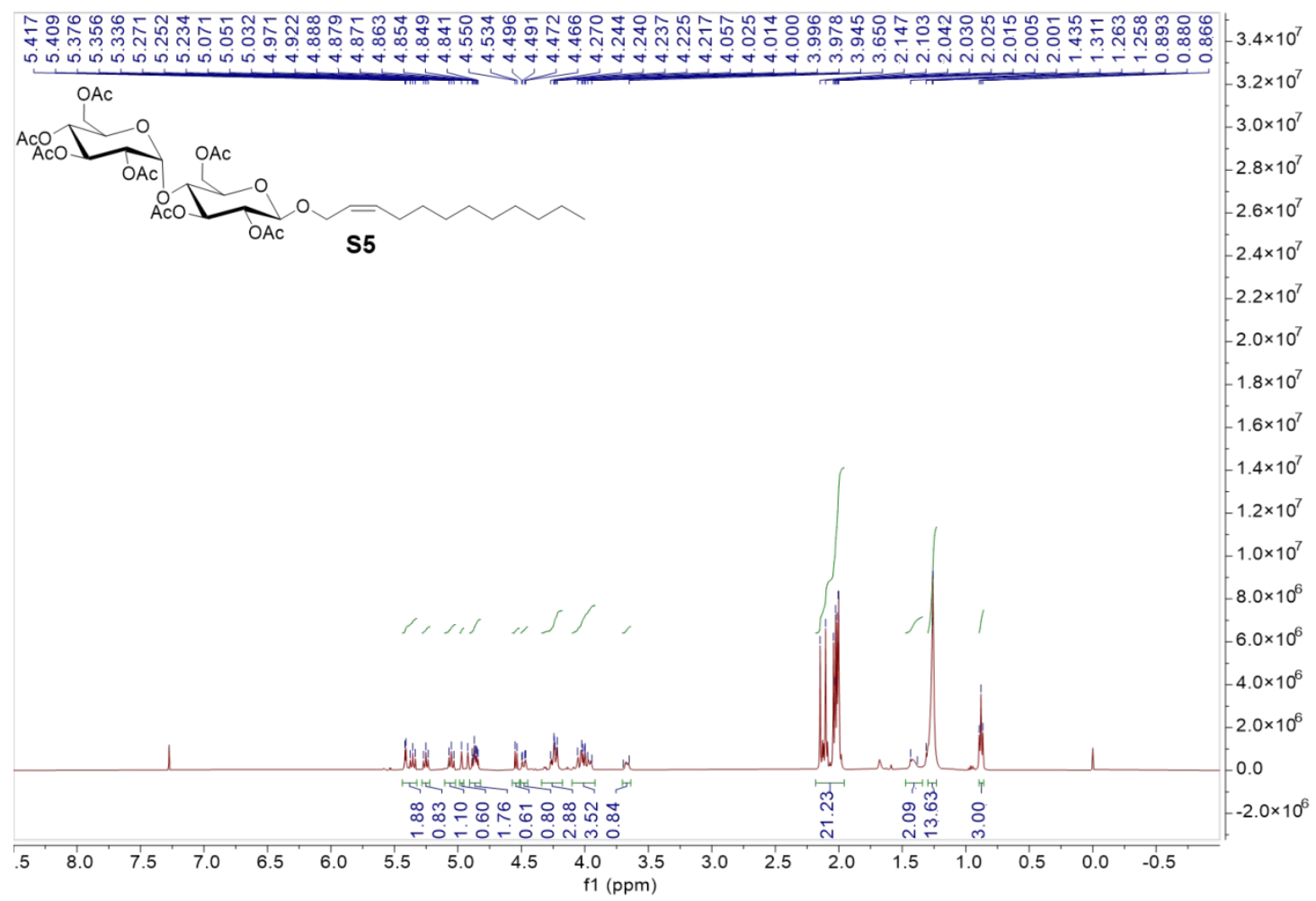

${ }^{1} \mathrm{H}$ NMR of $\mathbf{S 5}\left(\mathrm{CDCl}_{3}, 500 \mathrm{MHz}\right)$

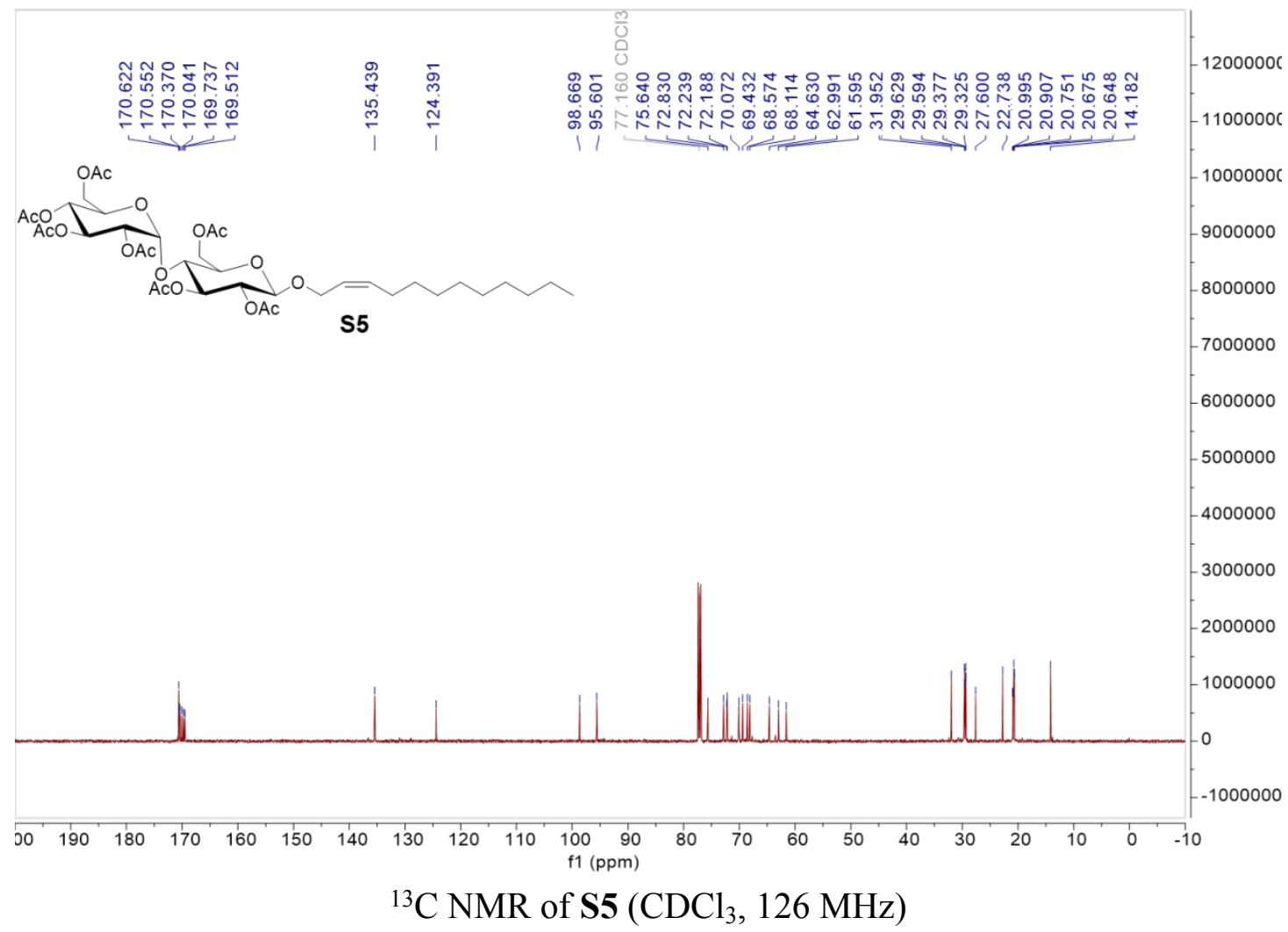




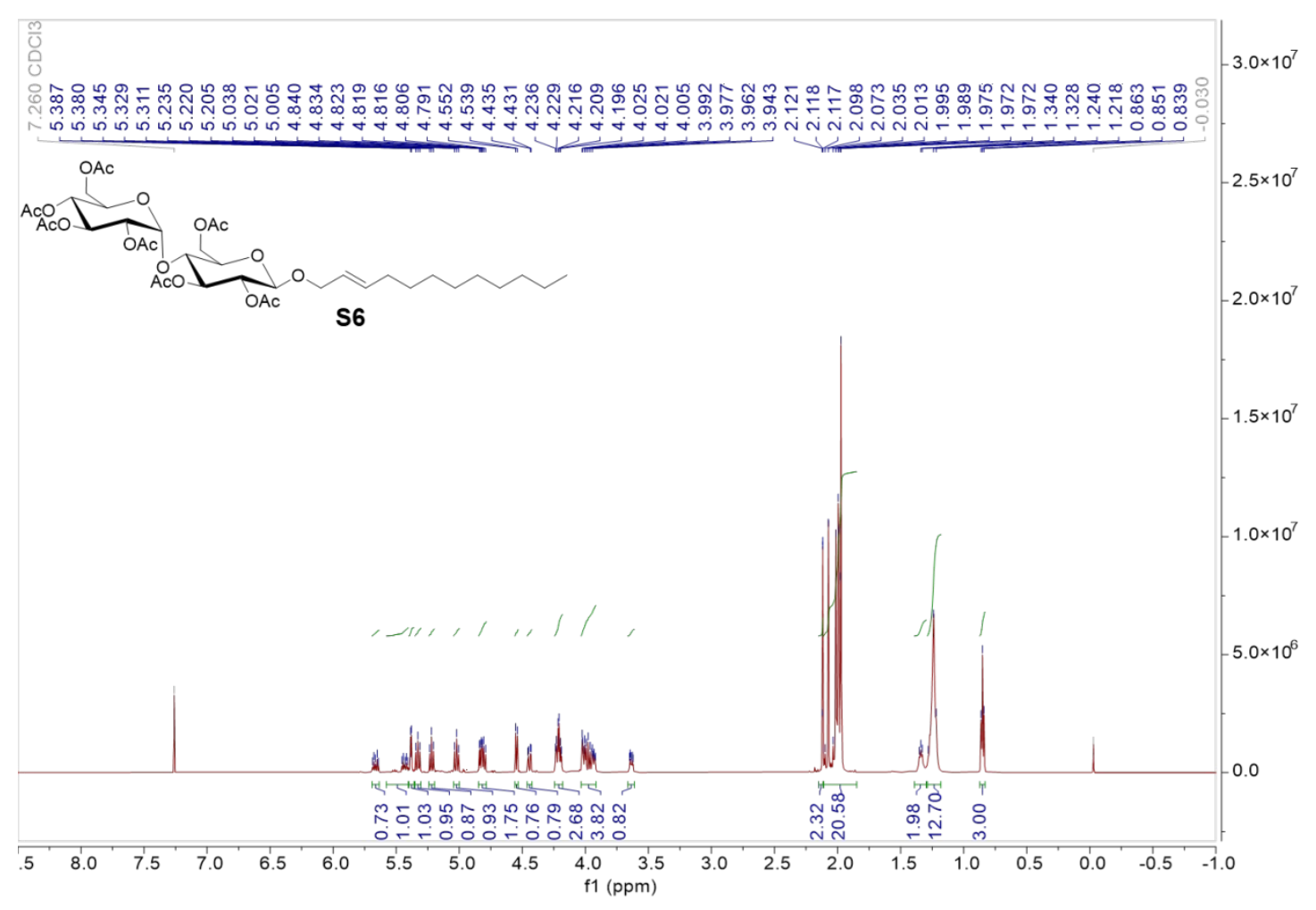

${ }^{1} \mathrm{H} \mathrm{NMR}$ of $\mathbf{S 6}\left(\mathrm{CDCl}_{3}, 500 \mathrm{MHz}\right)$

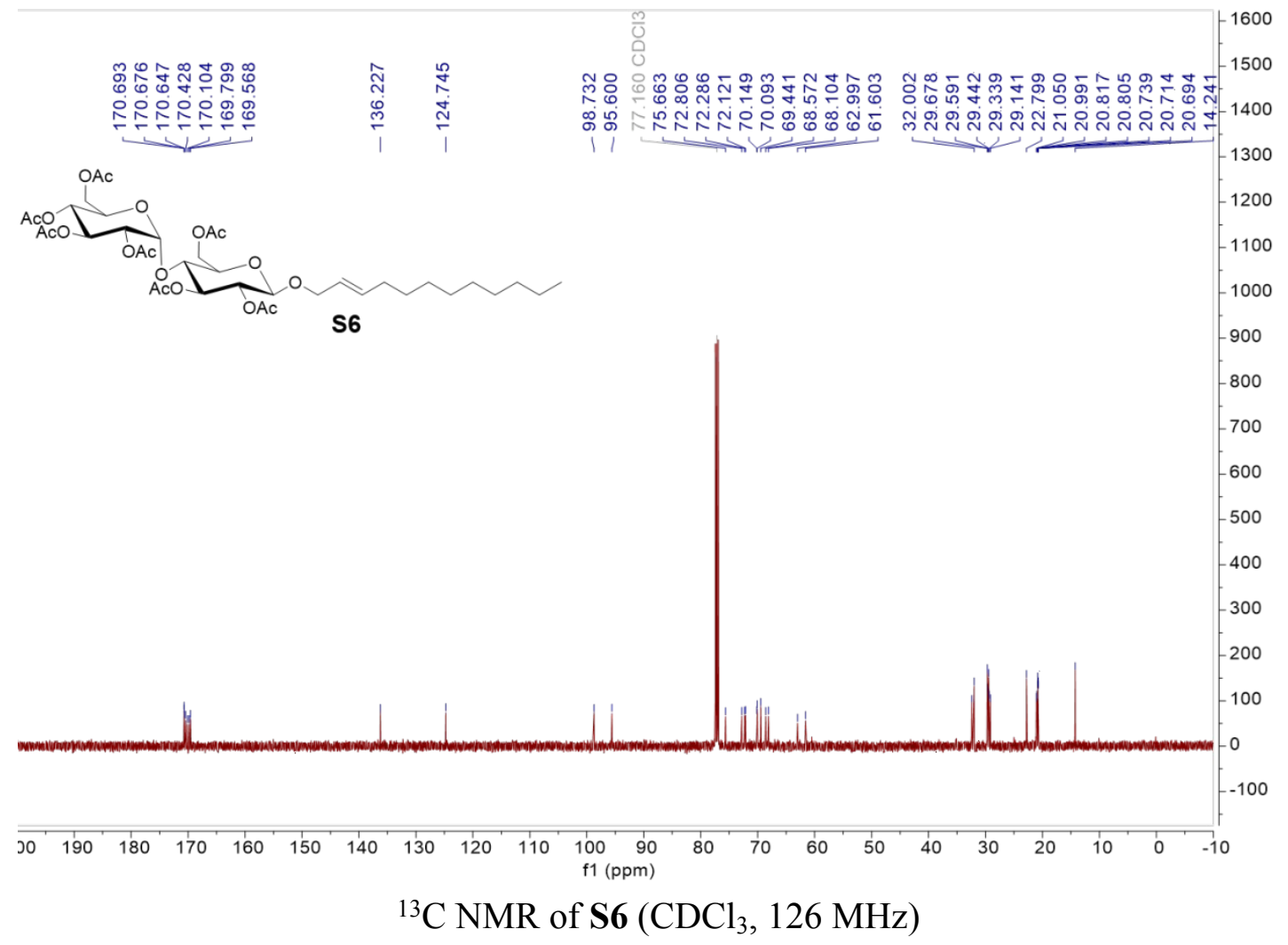




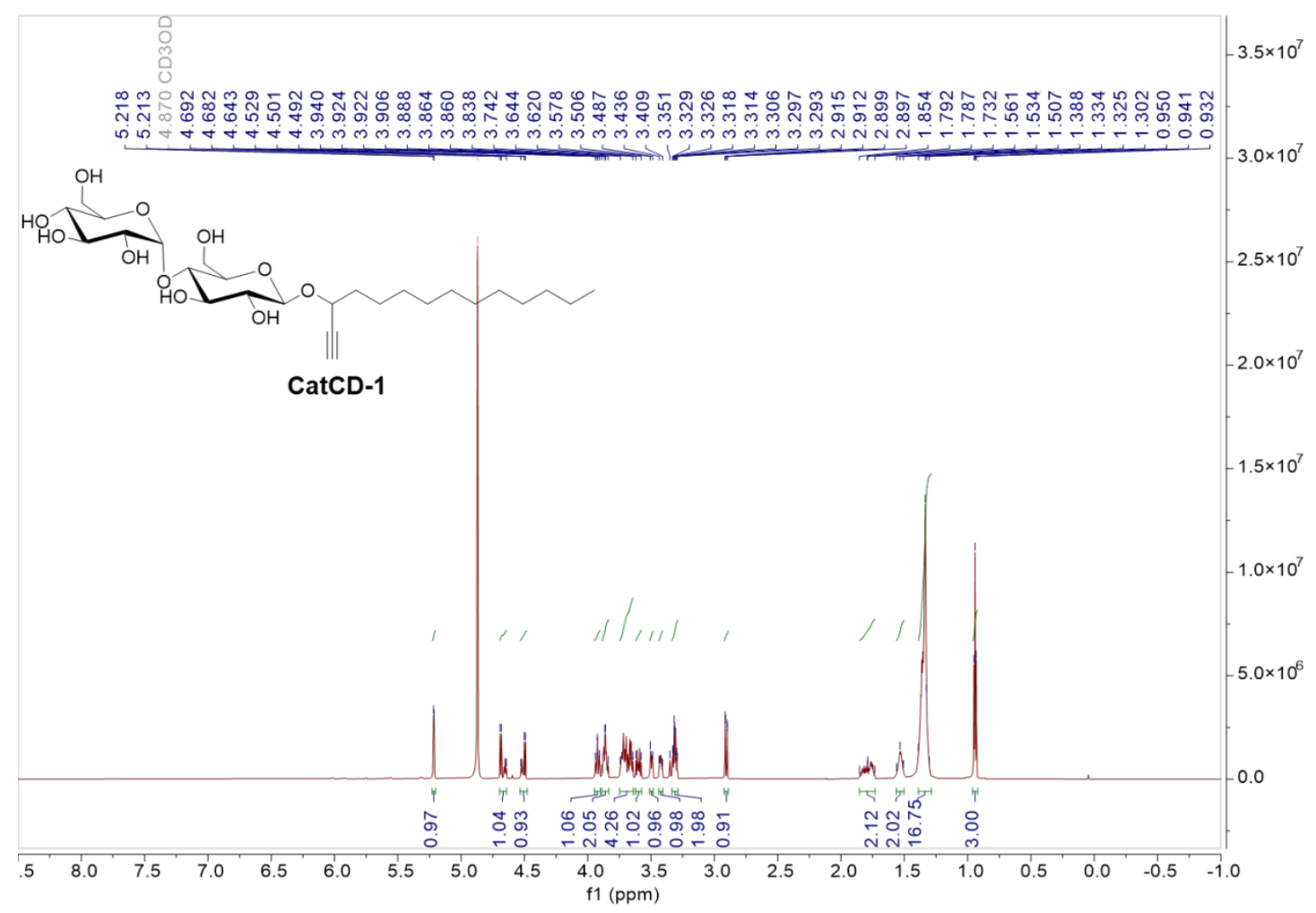

${ }^{1} \mathrm{H}$ NMR of CatCD-1 $\left(\mathrm{CD}_{3} \mathrm{OD}, 800 \mathrm{MHz}\right)$

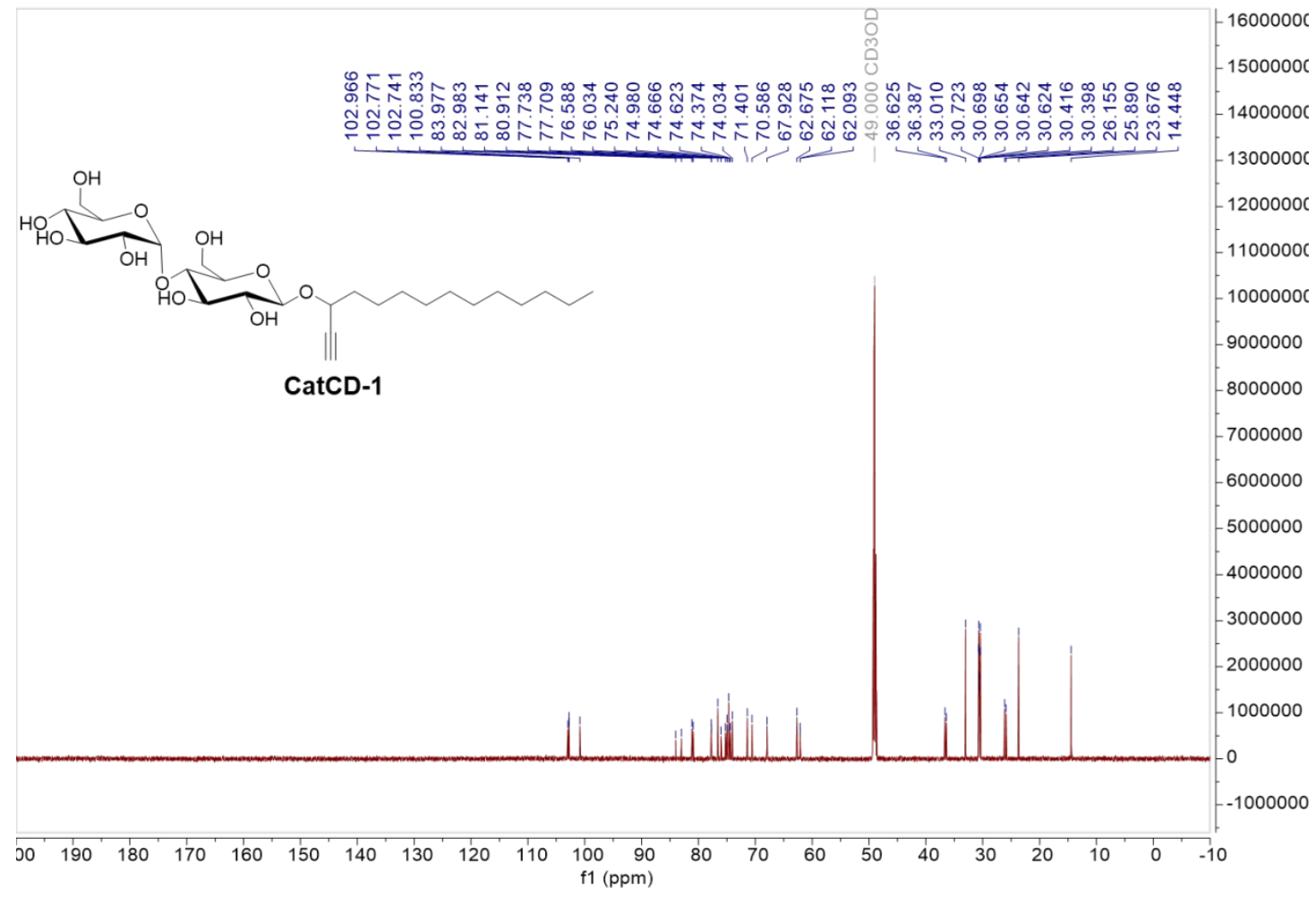

${ }^{13} \mathrm{C}$ NMR of CatCD-1 $\left(\mathrm{CD}_{3} \mathrm{OD}, 201 \mathrm{MHz}\right)$ 


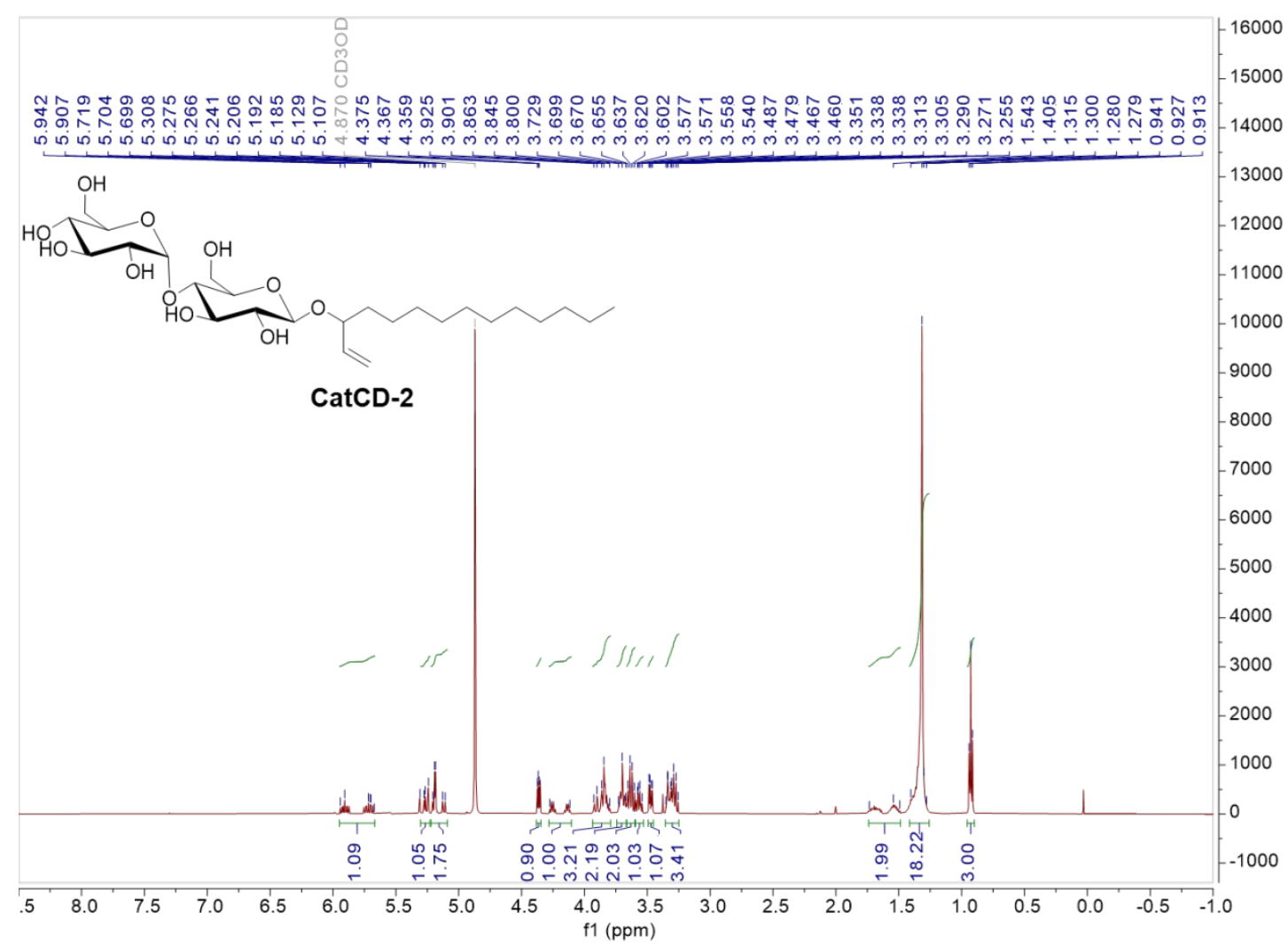

${ }^{1} \mathrm{H}$ NMR of CatCD-2 $\left(\mathrm{CD}_{3} \mathrm{OD}, 500 \mathrm{MHz}\right)$

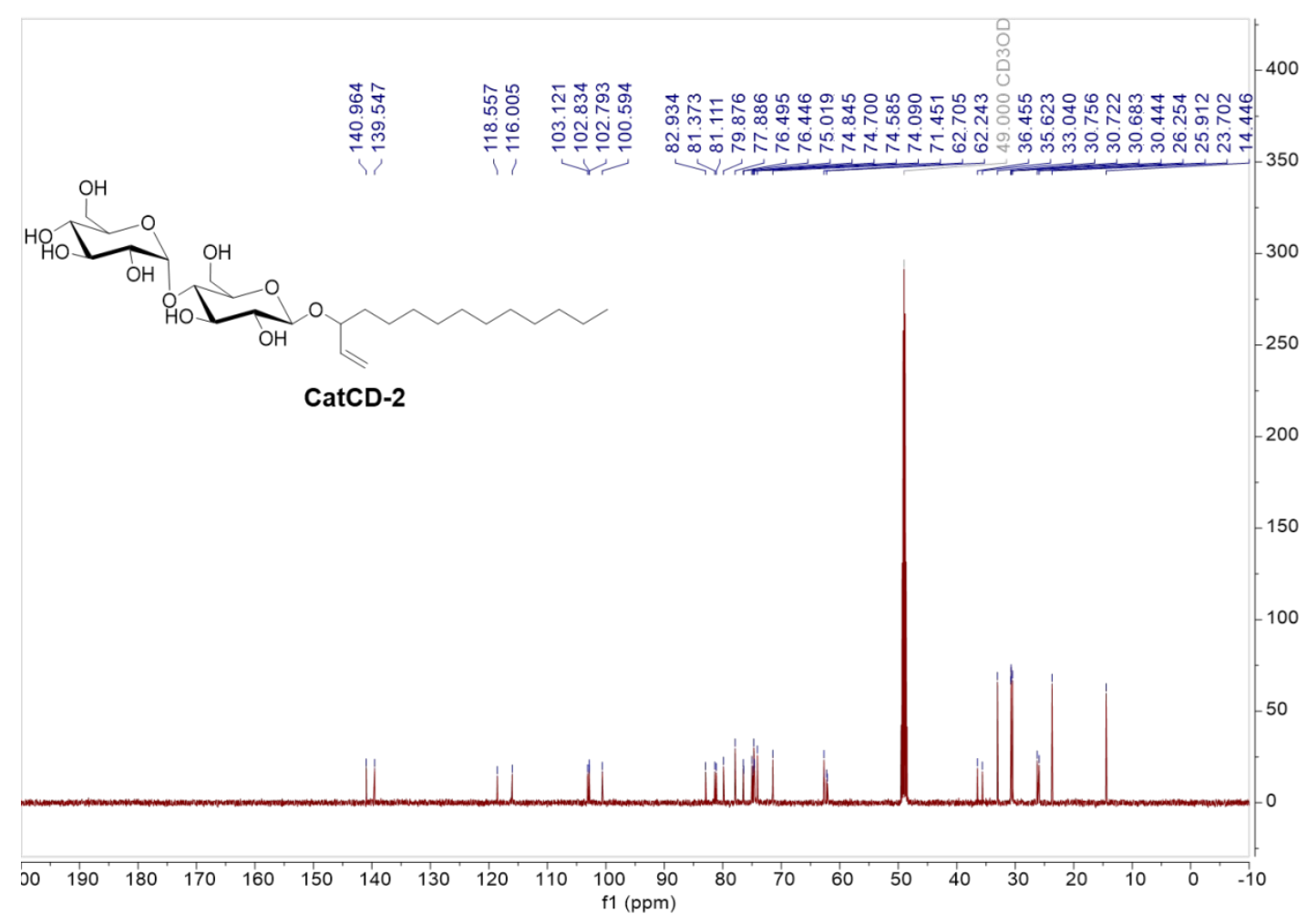

${ }^{13} \mathrm{C}$ NMR of CatCD-2 $\left(\mathrm{CD}_{3} \mathrm{OD}, 126 \mathrm{MHz}\right)$ 


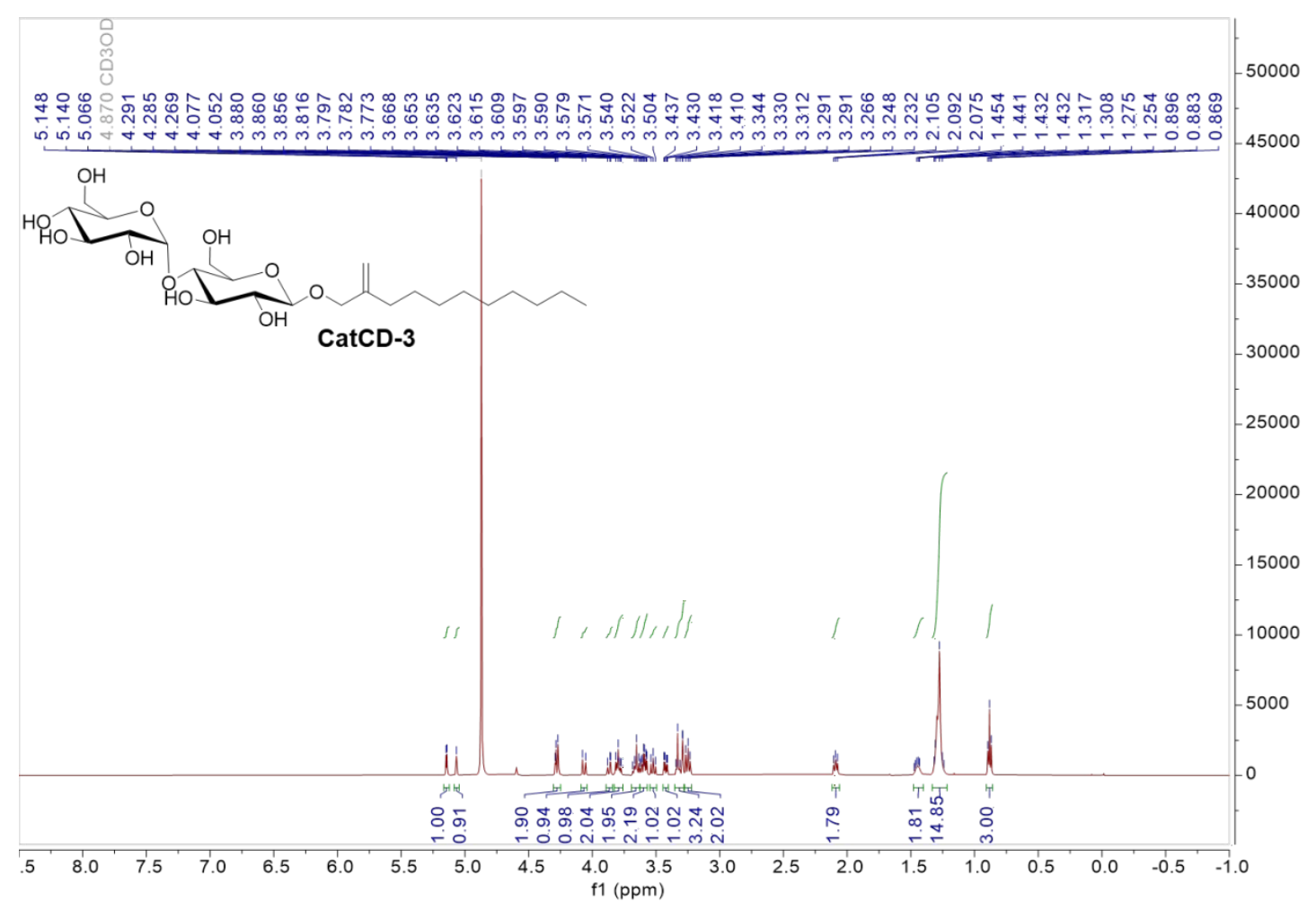

${ }^{1} \mathrm{H}$ NMR of CatCD-3 $\left(\mathrm{CD}_{3} \mathrm{OD}, 500 \mathrm{MHz}\right)$

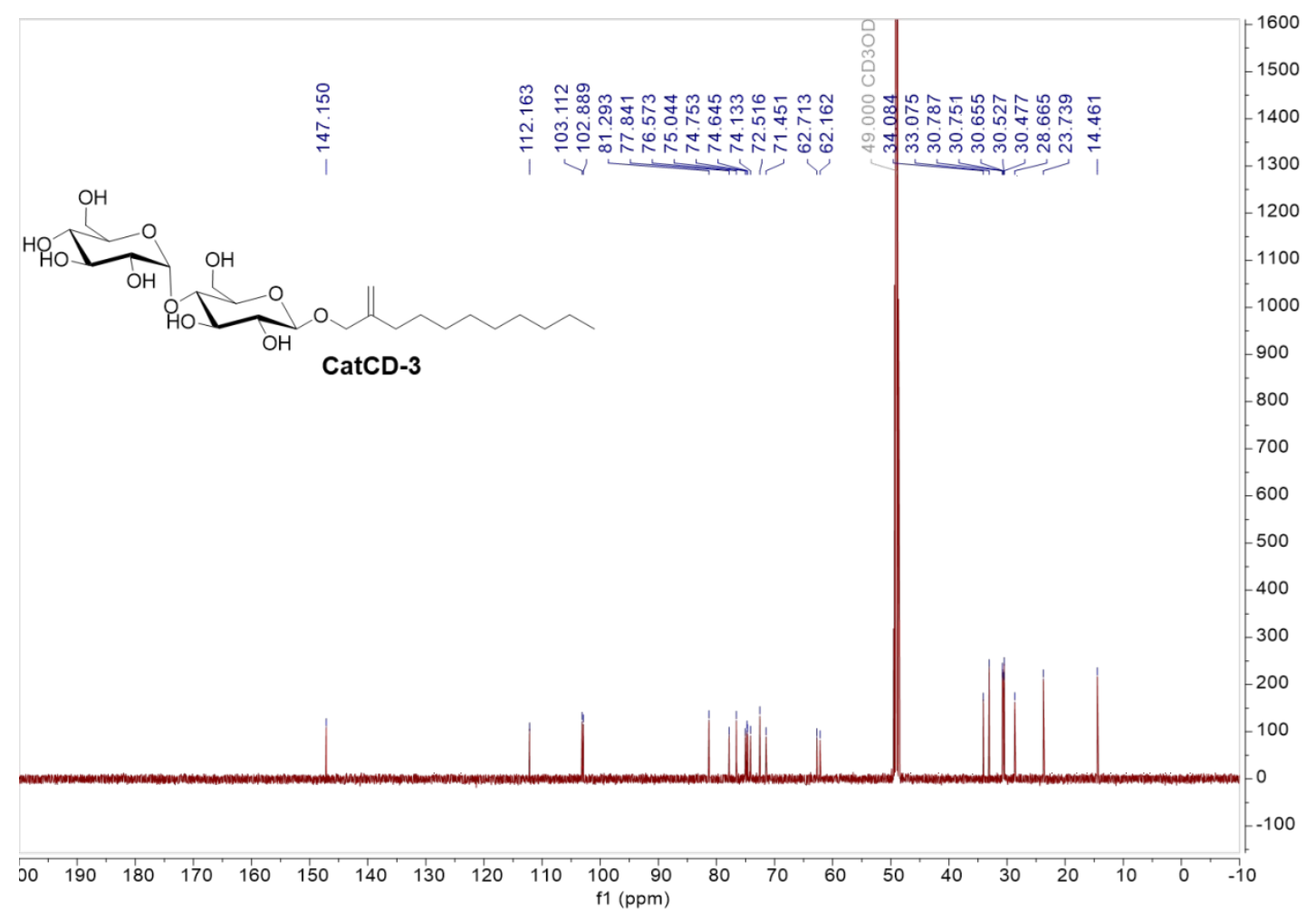

${ }^{13} \mathrm{C}$ NMR of CatCD-3 $\left(\mathrm{CD}_{3} \mathrm{OD}, 126 \mathrm{MHz}\right)$ 


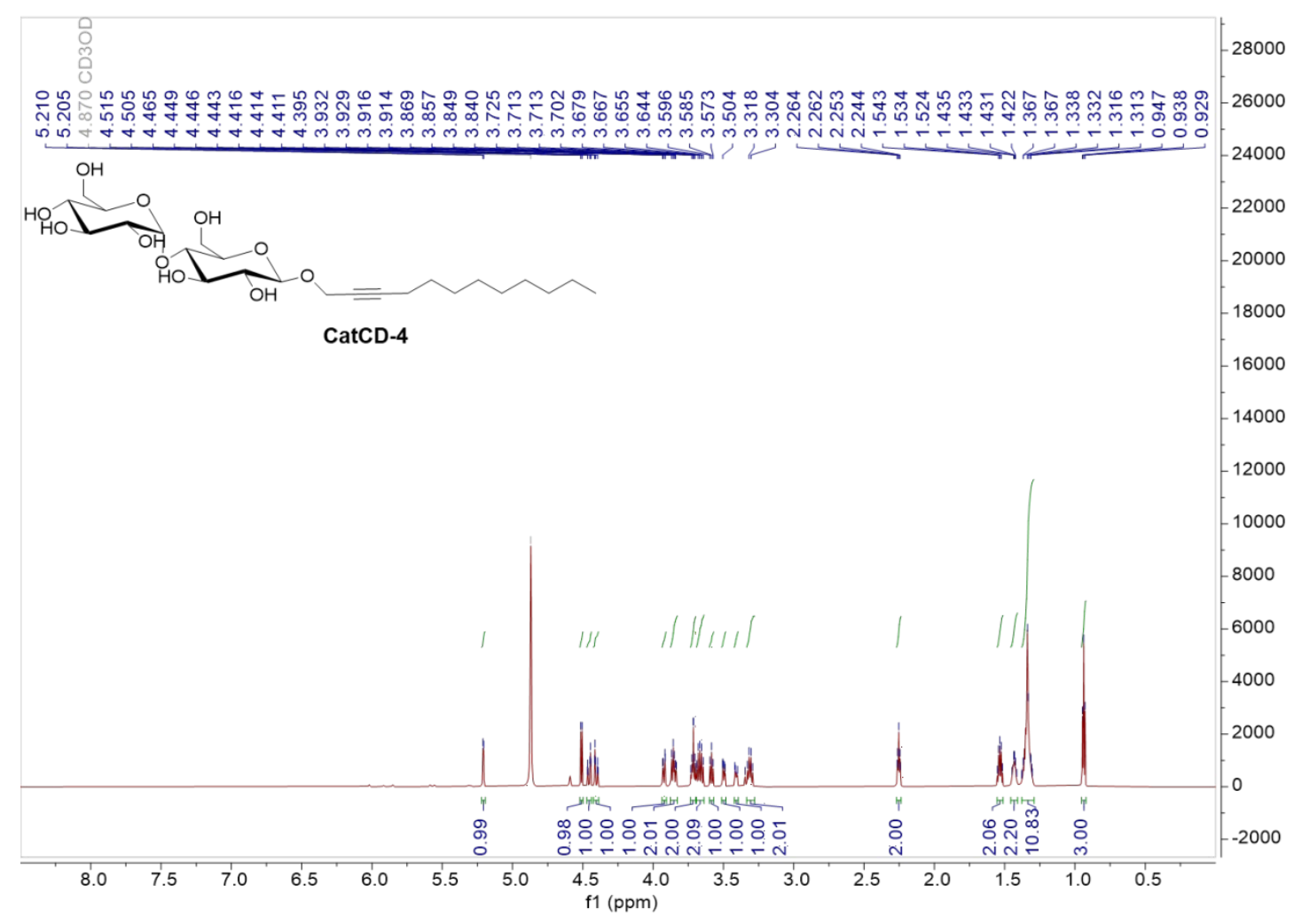

${ }^{1} \mathrm{H}$ NMR of CatCD-4 $\left(\mathrm{CD}_{3} \mathrm{OD}, 800 \mathrm{MHz}\right)$

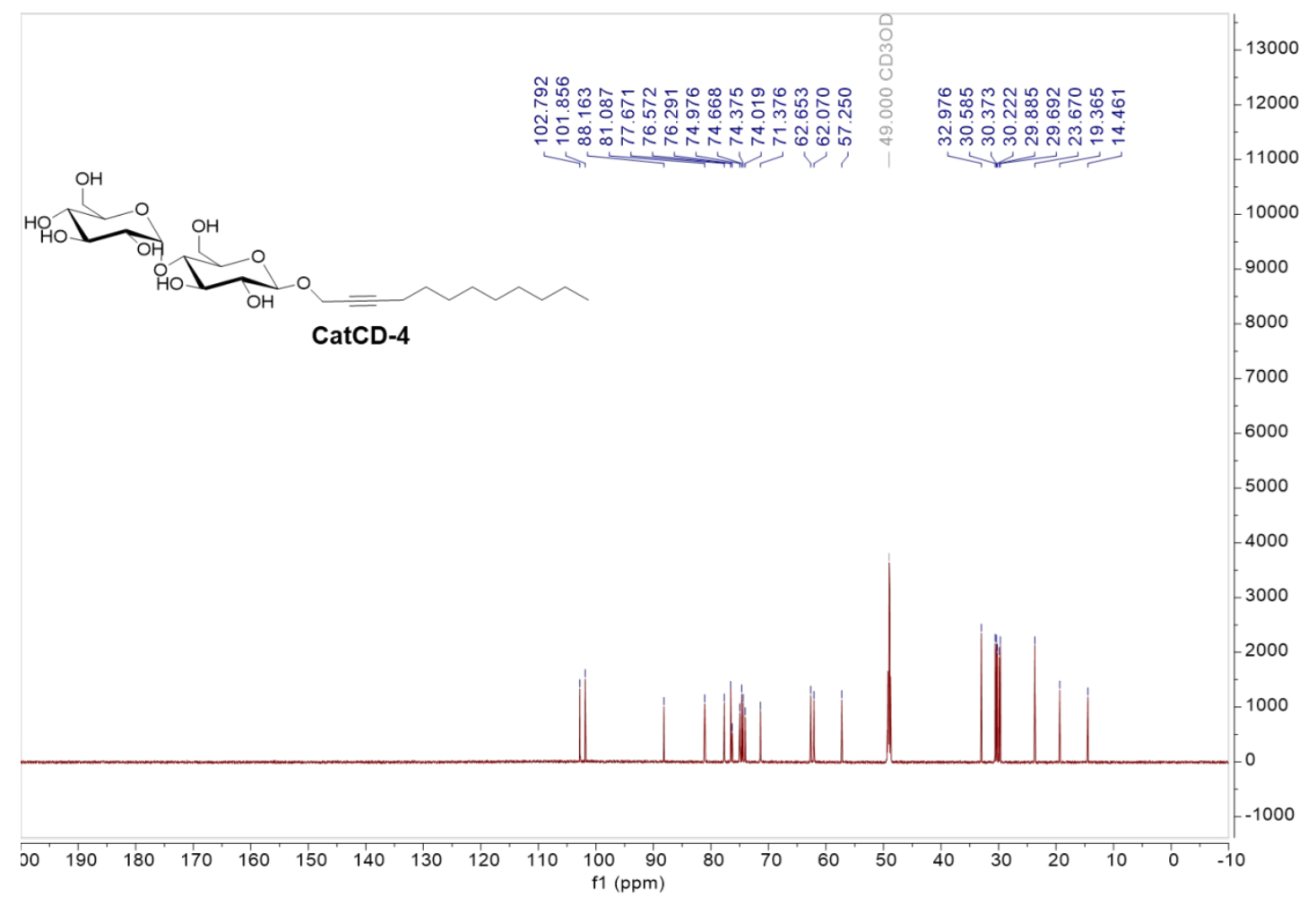

${ }^{13} \mathrm{C}$ NMR of CatCD-4 $\left(\mathrm{CD}_{3} \mathrm{OD}, 201 \mathrm{MHz}\right)$ 


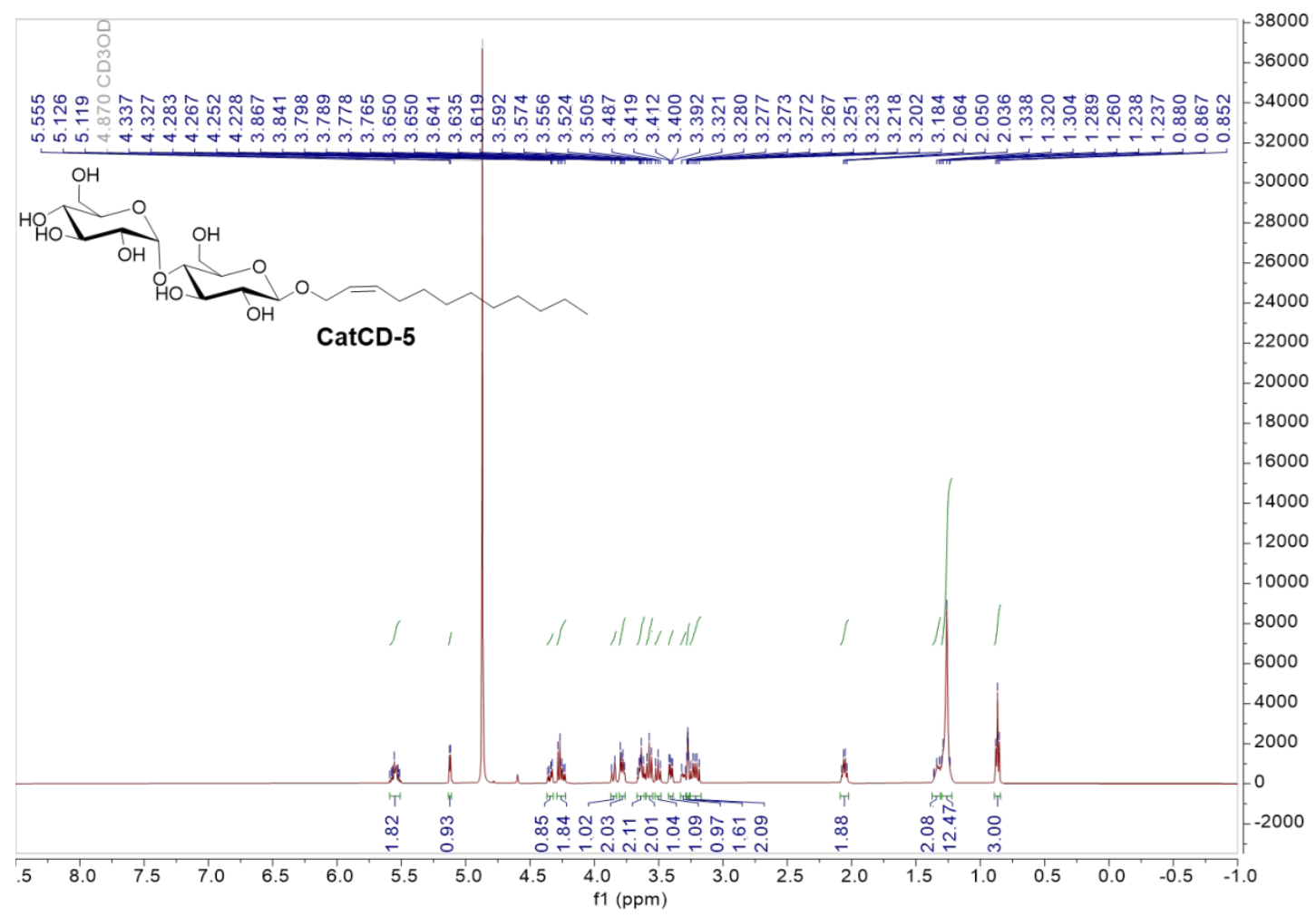

${ }^{1} \mathrm{H}$ NMR of CatCD-5 $\left(\mathrm{CD}_{3} \mathrm{OD}, 500 \mathrm{MHz}\right)$

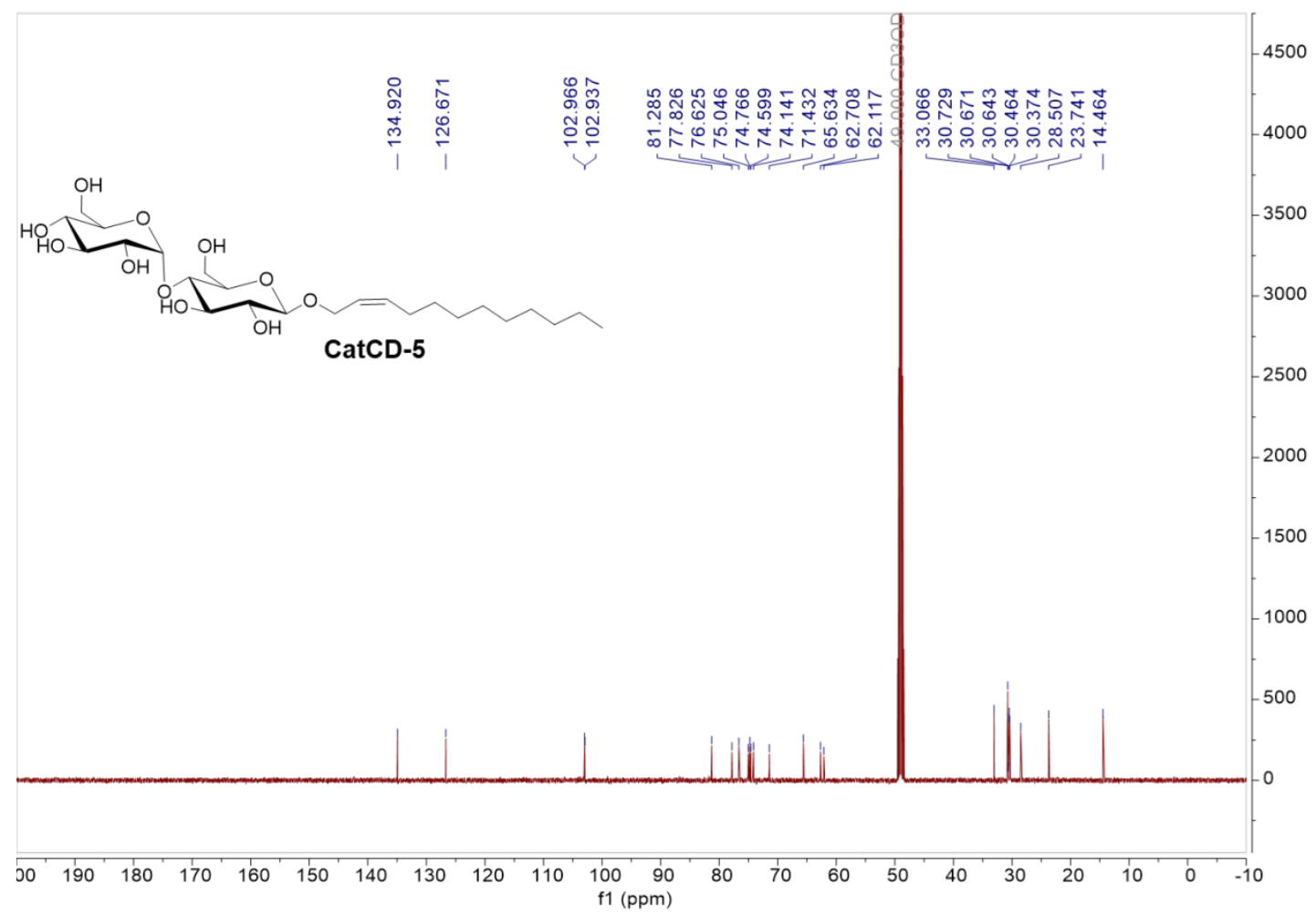

${ }^{13} \mathrm{C}$ NMR of CatCD-5 $\left(\mathrm{CD}_{3} \mathrm{OD}, 126 \mathrm{MHz}\right)$ 


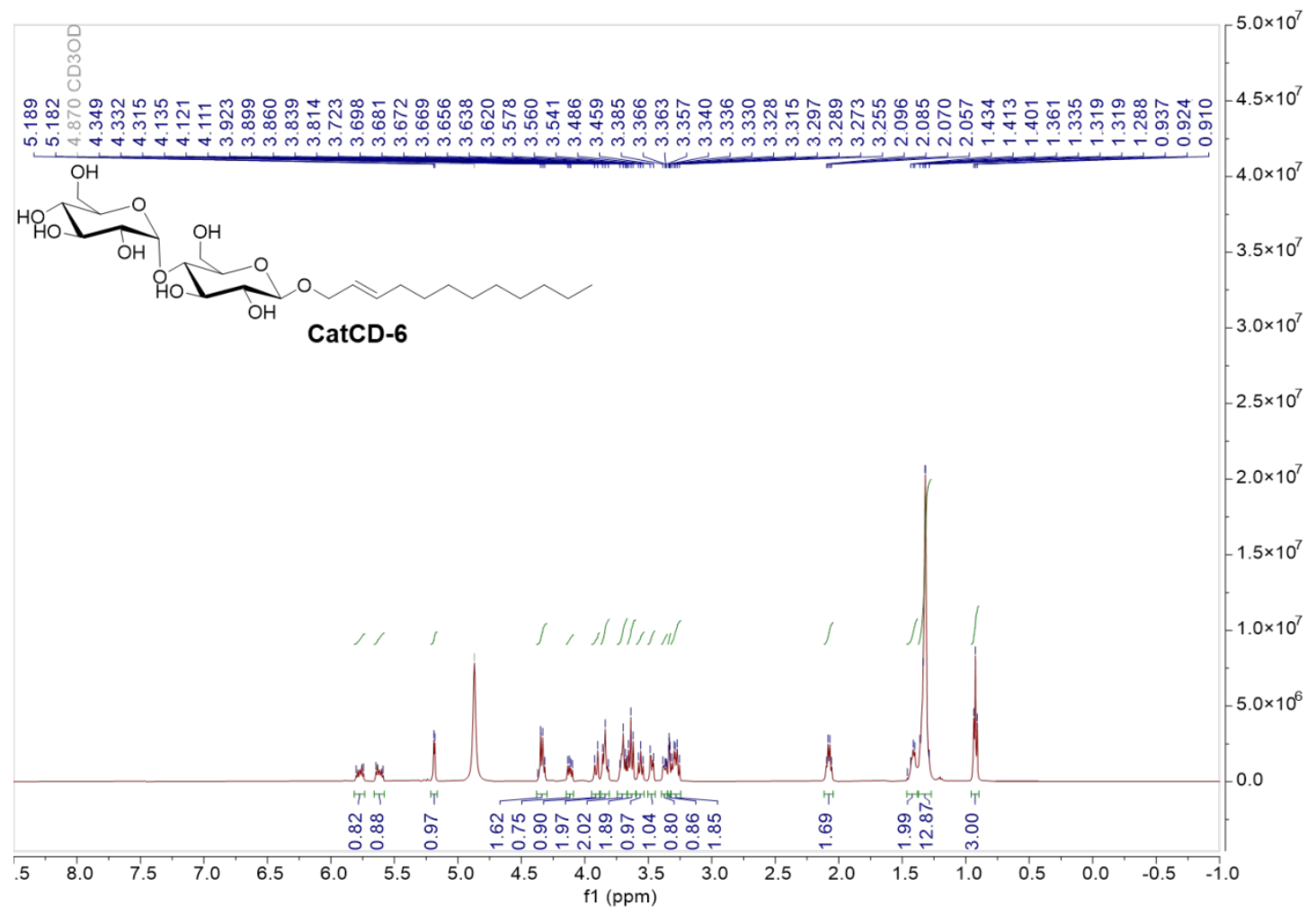

${ }^{1} \mathrm{H}$ NMR of CatCD-6 $\left(\mathrm{CD}_{3} \mathrm{OD}, 500 \mathrm{MHz}\right)$

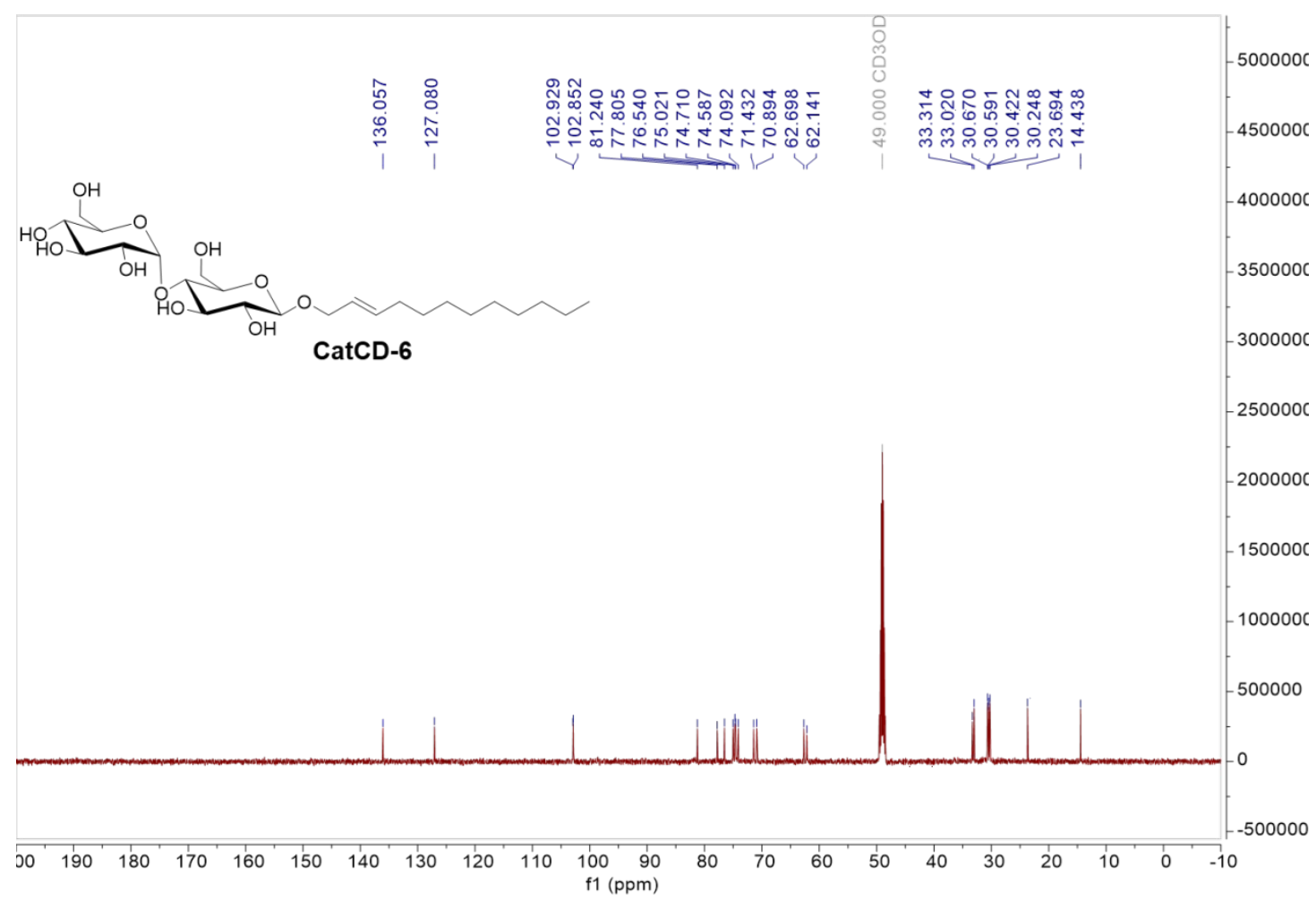

${ }^{13} \mathrm{C}$ NMR of CatCD-6 $\left(\mathrm{CD}_{3} \mathrm{OD}, 126 \mathrm{MHz}\right)$ 


\section{Purification Characterization}

\section{$<$ AD2 >}

$\mathrm{mV}$

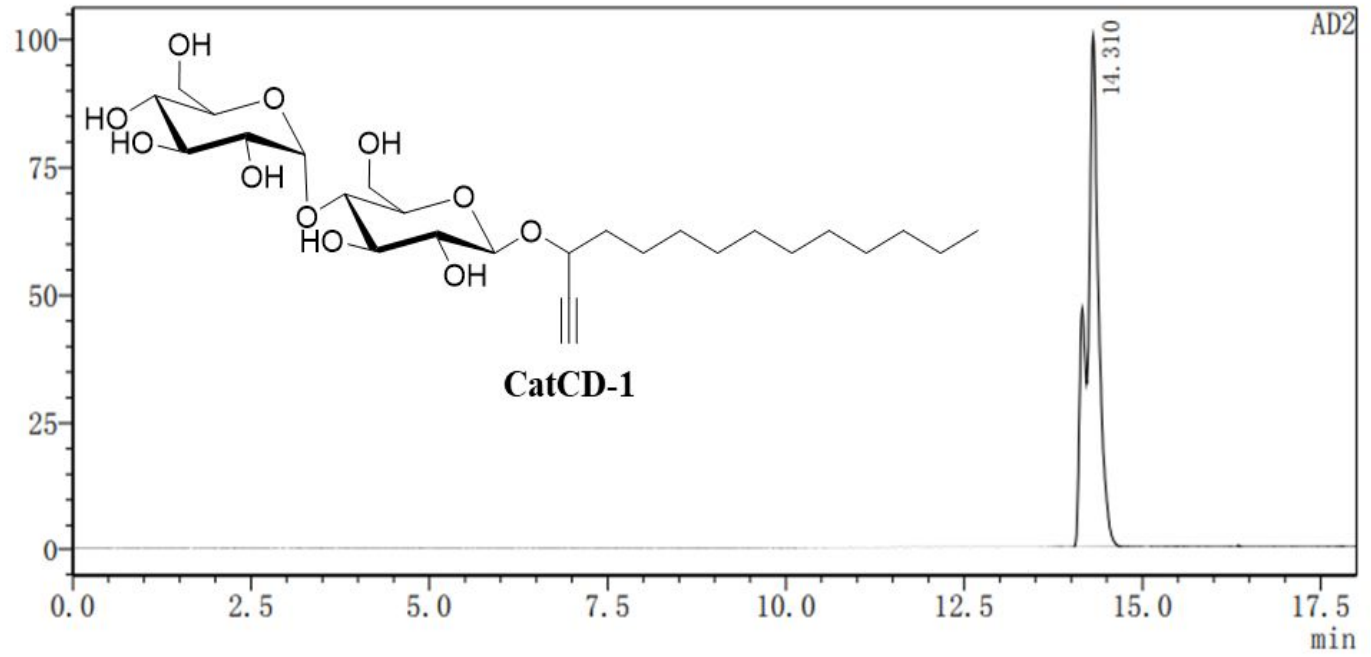

AD2

\begin{tabular}{|c|c|c|c|c|c|}
\hline Peak\# & Ret. Time (min) & Height(mAU) & Height\% & Area(mAU*s) & Area\% \\
\hline 1 & 14.310 & 99979 & 100.000 & 1162587 & 100.000 \\
\hline 总计 & & 99979 & 100.000 & 1162587 & 100.000 \\
\hline
\end{tabular}

$<$ AD2 $>$

$\mathrm{mV}$

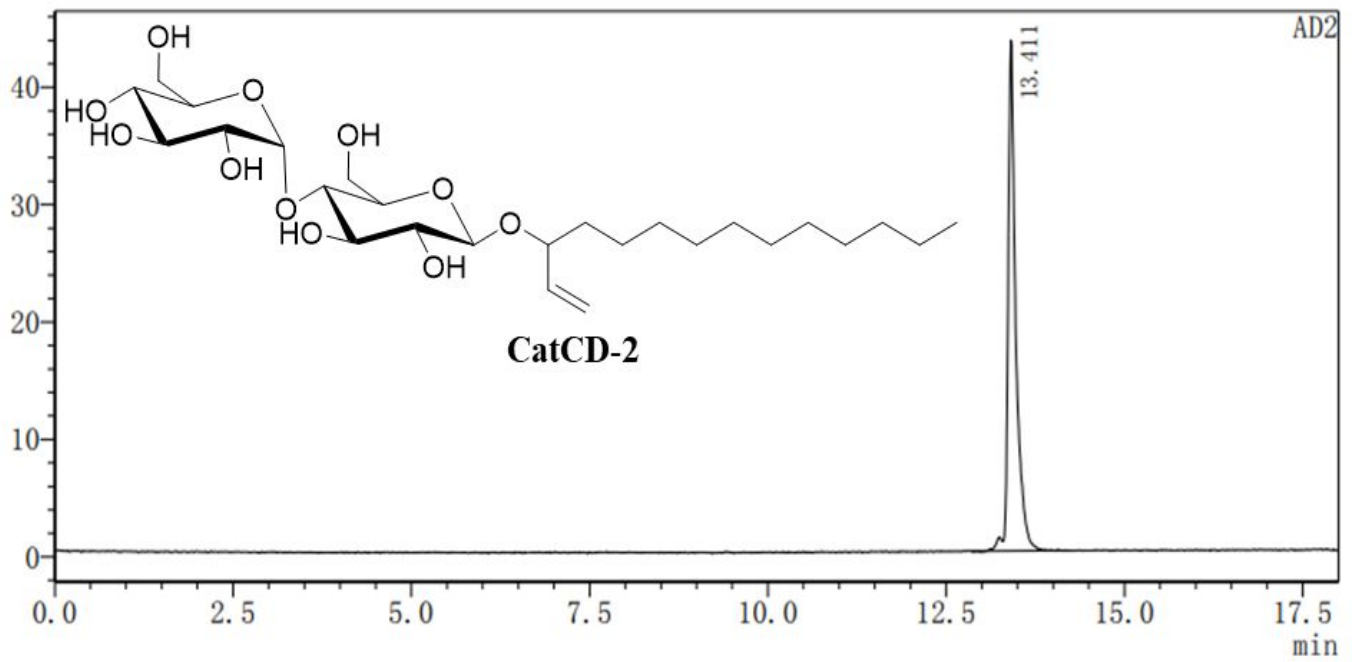

AD2

\begin{tabular}{|c|c|c|c|c|c|}
\hline Peak\# & Ret. Time (min) & Height(mAU) & Height $\%$ & Area(mAU*s) & Area\% \\
\hline 1 & 13.411 & 43547 & 100.000 & 325817 & 100.000 \\
\hline 总计 & & 43547 & 100.000 & 325817 & 100.000 \\
\hline
\end{tabular}


<AD2>

$\mathrm{mV}$

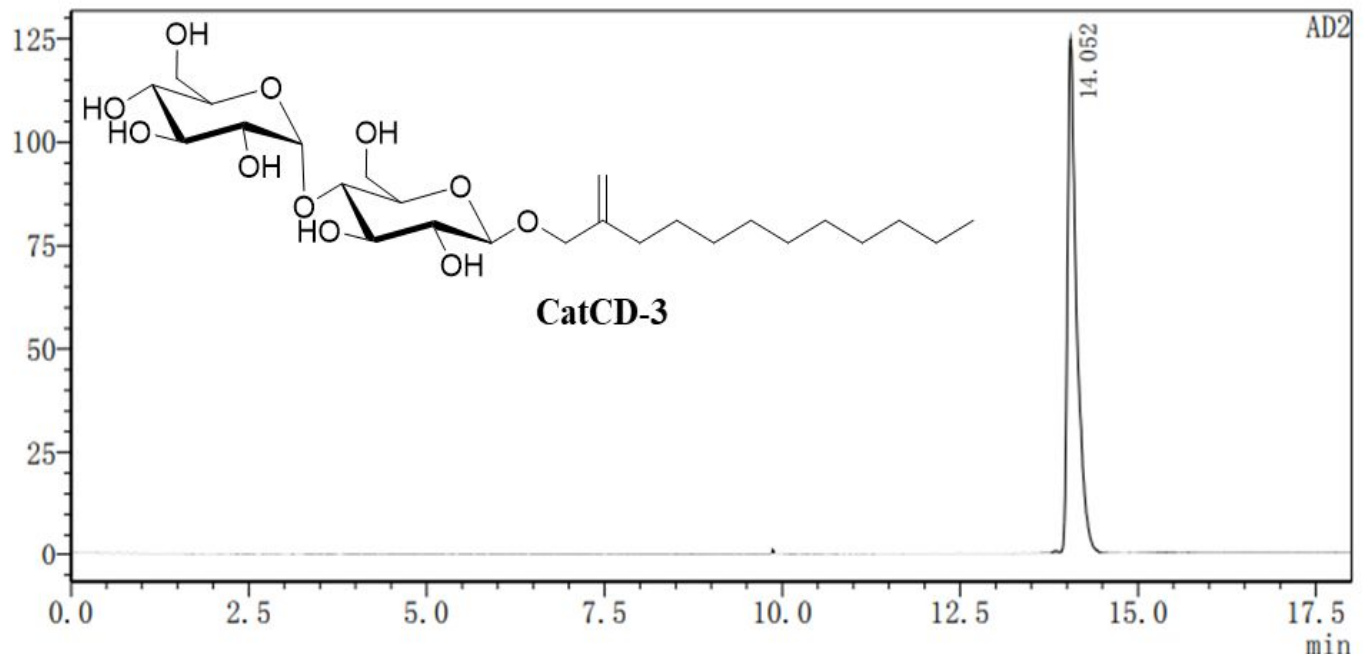

AD2

\begin{tabular}{|c|c|c|c|c|c|}
\hline Peak\# & Ret. Time (min) & Height(mAU) & Height\% & Area(mAU*s) & Area\% \\
\hline 1 & 14.052 & 124354 & 100.000 & 1119900 & 100.000 \\
\hline 总计 & & 124354 & 100.000 & 1119900 & 100.000 \\
\hline
\end{tabular}

\section{<AD2>}

$\mathrm{mV}$

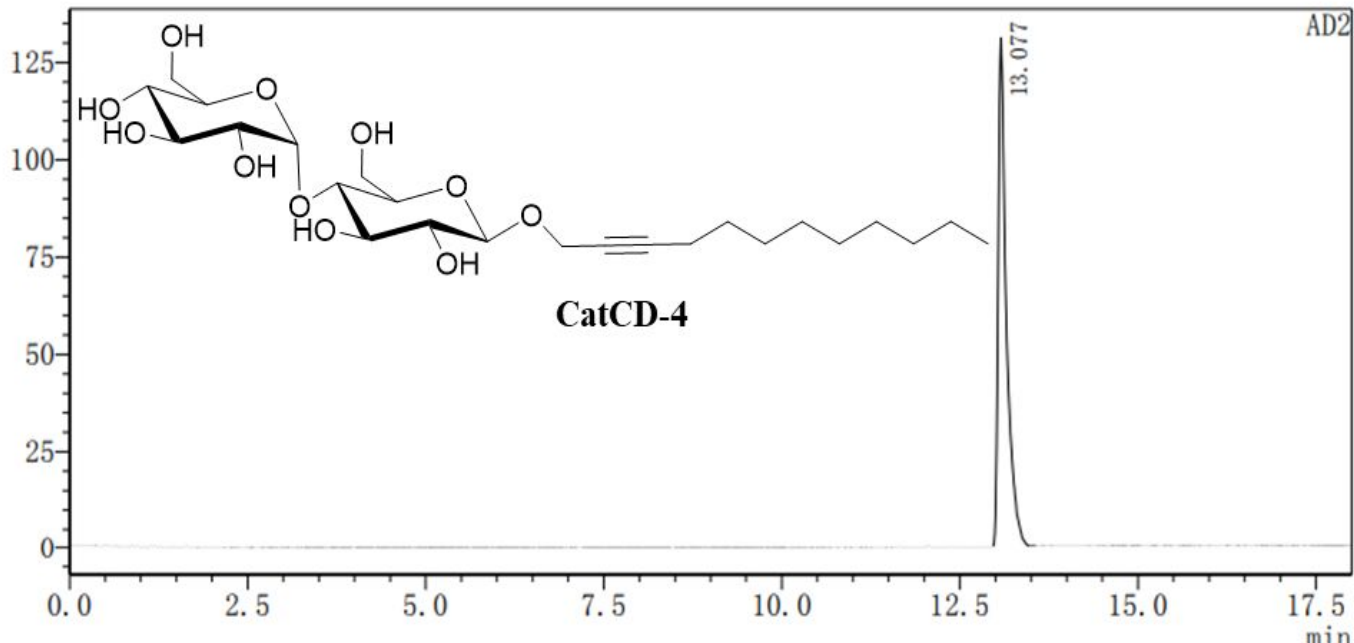

AD2

\begin{tabular}{|c|c|c|c|c|c|}
\hline Peak\# & Ret. Time (min) & Height(mAU) & Height $\%$ & Area(mAU*s) & Area\% \\
\hline 1 & 13.077 & 131003 & 100.000 & 1048518 & 100.000 \\
\hline 总计 & & 131003 & 100.000 & 1048518 & 100.000 \\
\hline
\end{tabular}


<AD2>

$\mathrm{mV}$

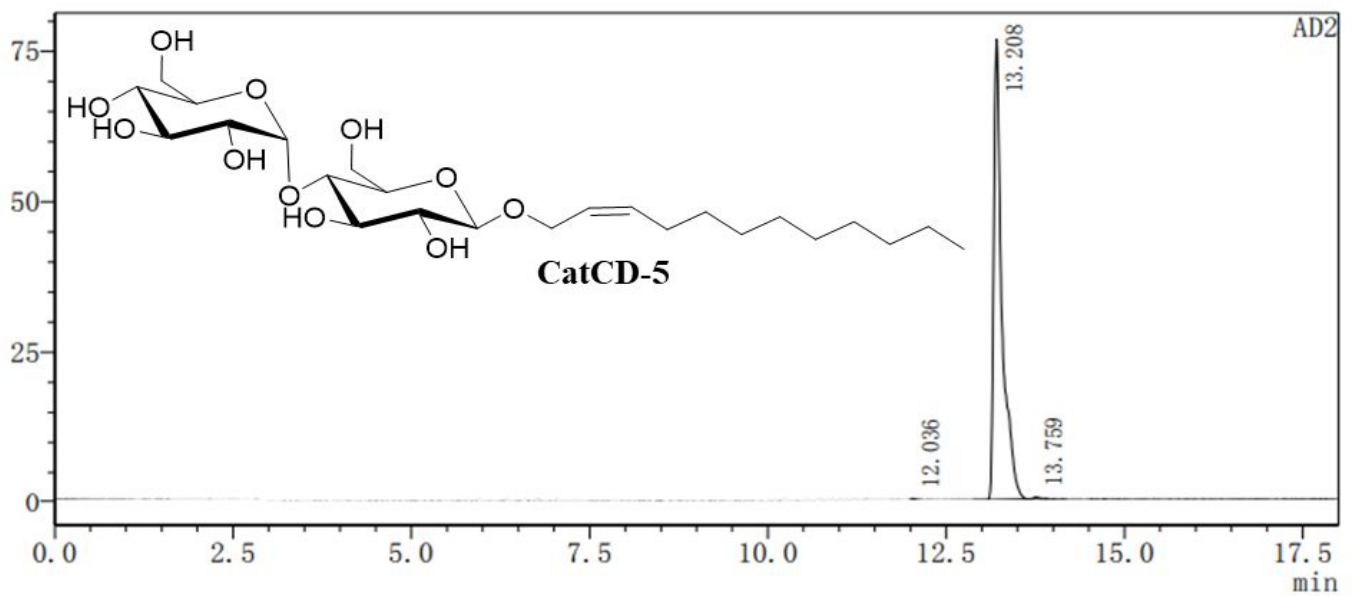

AD2

\begin{tabular}{|c|c|c|c|c|c|}
\hline Peak\# & Ret. Time (min) & Height(mAU) & Height\% & Area(mAU*s) & Area\% \\
\hline 1 & 12.036 & 261 & 0.337 & 1616 & 0.260 \\
\hline 2 & 13.208 & 76573 & 99.139 & 615895 & 99.127 \\
\hline 3 & 13.759 & 405 & 0.524 & 3809 & 0.613 \\
\hline 总计 & & 77238 & 100.000 & 621320 & 100.000 \\
\hline
\end{tabular}

<AD2>

$\mathrm{mV}$

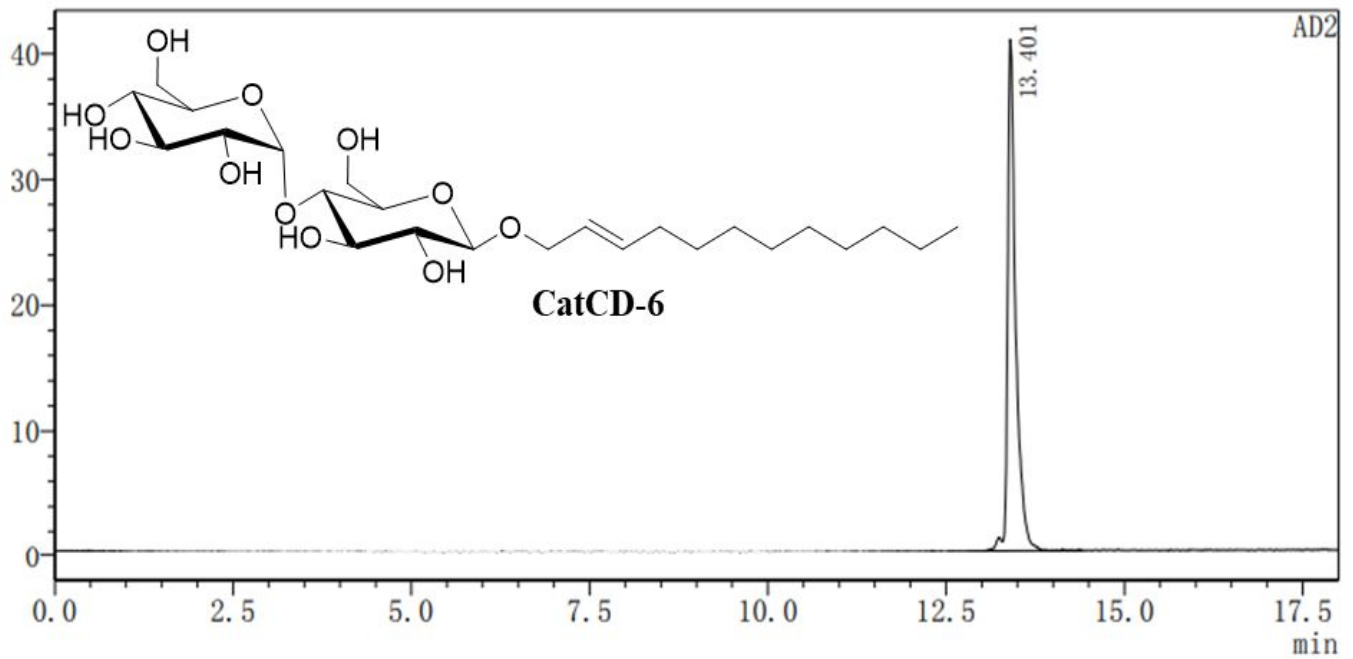

AD2

\begin{tabular}{|c|c|c|c|c|c|}
\hline Peak\# & Ret. Time (min) & Height(mAU) & Height $\%$ & Area(mAU*s) & Area\% \\
\hline 1 & 13.401 & 40694 & 100.000 & 317547 & 100.000 \\
\hline 总计 & & 40694 & 100.000 & 317547 & 100.000 \\
\hline
\end{tabular}




\section{References}

1. Shiina, I.; Umezaki, Y.; Kuroda, N.; Iizumi, T.; Nagai, S.; Katoh, T., MNBAMediated $\beta$-Lactone Formation: Mechanistic Studies and Application for the Asymmetric Total Synthesis of Tetrahydrolipstatin. J. Org. Chem. 2012, 77, 4885-4901.

2. Liu, L.; Bao, X.; Xiao, H.; Li, J.; Ye, F.; Wang, C.; Cai, Q.; Fan, S., CopperCatalyzed Perfluoroalkylation of Allyl Phosphates with Stable Perfluoroalkylzinc Reagents. J. Org. Chem. 2019, 84, 423-434.

3. Wang, T. C.; Fan, L. F.; Shen, Y.; Wang, P. S.; Gong, L. Z., Asymmetric Allylic C-H Alkylation of Allyl Ethers with 2-Acylimidazoles. J. Am. Chem. Soc. 2019, 141, 10616-10620.

4. Steib, P.; Breit, B., Concise Total Synthesis of (-)-Vermiculine through a RhodiumCatalyzed $C_{2}$-Symmetric Dimerization Strategy. Chem. Eur. J. 2019, 25, 3532-3535.

5. leftheriadis, N.; Thee, S. A.; Zwinderman, M. R. H.; Leus, N. G. J.; Dekker, F. J. J. A. C., Activity-Based Probes for 15-Lipoxygenase-1. Angew. Chem., Int. Ed. Engl. 2016, $55,12300-12305$.

6. Yoshida, T.; Murai, M.; Abe, M.; Ichimaru, N.; Harada, T.; Nishioka, T.; Miyoshi, H. J. B., Crucial Structural Factors and Mode of Action of Polyene Amides as Inhibitors for Mitochondrial NADH-Ubiquinone Oxidoreductase (Complex I). Biochemistry 2007, 46, 10365-10372.

7. McTeague, T. A.; Jamison, T. F., Photoredox Activation of $\mathrm{SF}_{6}$ for Fluorination. Angew. Chem., Int. Ed. Engl. 2016, 55, 15072-15075. 